\title{
Nitrogen starvation-induced transcriptome alterations and influence of transcription regulator mutants in Mycobacterium smegmatis
}

\author{
Nadja Jeßberger', Yinhua Lu, ${ }^{1,2}$, Johannes Amon ${ }^{1}$, Fritz Titgemeyer ${ }^{3}$, Sophia Sonnewald ${ }^{4}$, Stephen Reid ${ }^{4}$
} and Andreas Burkovski ${ }^{1^{*}}$

\begin{abstract}
Background: As other bacteria, Mycobacterium smegmatis needs adaption mechanisms to cope with changing nitrogen sources and to survive situations of nitrogen starvation. In the study presented here, transcriptome analyses were used to characterize the response of the bacterium to nitrogen starvation and to elucidate the role of specific transcriptional regulators.

Results: In response to nitrogen deprivation, a general starvation response is induced in M. smegmatis. This includes changes in the transcription of several hundred genes encoding e.g. transport proteins, proteins involved in nitrogen metabolism and regulation, energy generation and protein turnover. The specific nitrogen-related changes at the transcriptional level depend mainly on the presence of $\mathrm{G} \ln R$, while the AmtR protein controls only a small number of genes.

Conclusions: M. smegmatis is able to metabolize a number of different nitrogen sources and nitrogen control in M. smegmatis is similar to control mechanisms characterized in streptomycetes, while the master regulator of nitrogen control in corynebacteria, AmtR, is plays a minor role in this regulatory network.
\end{abstract}

Keywords: AmtR, GlnR, Nitrogen control, Nitrogen metabolism, OmpR/EnvZ

\section{Background}

Nitrogen is one of the macro-elements of life and constituent of numerous cellular metabolites (e.g. amino acids, amino sugars, nucleotides) and macro-molecules (proteins, peptidoglycan, DNA, mRNA). Therefore, its supply is crucial for organisms. Bacteria are able to use a number of different nitrogen sources to cover their nitrogen requirements; however, in most species metabolism is biased in favor of ammonium. When ammonium becomes limiting, typical bacterial responses to this situation include the expression and activation of ammonium carriers and high affinity ammonium assimilation enzymes as well as expression of carriers and enzymes for the use of alternative nitrogen sources. This response, designated as nitrogen control, is governed by different types of

\footnotetext{
* Correspondence: aburkov@biologie.uni-erlangen.de

${ }^{1}$ Lehrstuhl für Mikrobiologie, Friedrich-Alexander-Universität

Erlangen-Nürnberg, Erlangen, Germany

Full list of author information is available at the end of the article
}

transcriptional regulators. In respect to these transcription control proteins, Actinobacteria are divided into two major groups, one comprising GlnR and the other AmtR as master regulators of nitrogen control. GlnR was described for example in Streptomyces coelicolor, Streptomyces venezuelae, Amycolatopsis mediterranei and Mycobacterium tuberculosis, while AmtR controls nitrogen regulation in corynebacteria such as Corynebacterium diphtheriae, Corynebacterium efficiens and Corynebacterium glutamicum [1].

In S. coelicolor the OmpR-type regulator GlnR acts as a transcriptional activator for at least 15 genes, encoding proteins related to nitrogen uptake, metabolism and regulation as well as proteins with unknown function $[2,3]$. Proteomics analyses indicated broader regulatory influence, e.g. on amino acid and carbon metabolism [4]. S. coelicolor exhibits a second GlnR-type regulator, designated GlnRII, which was shown to bind to the upstream regions of the $a m t B-g \ln K-g \ln D$ operons and the 
$g \ln A$ and $g \ln I I$ gene $[2,3,5]$. The regulatory function of this protein is still unknown.

In corynebacteria, like the amino acid producing strains C. glutamicum and C. efficiens or the pathogen C. diphtheriae, expression of genes coding for proteins for uptake and assimilation of nitrogen sources is under control of the TetR-type regulator AmtR [6-8]. In C. glutamicum AmtR blocks transcription of at least 35 genes during sufficient ammonium supply $[9,10]$. The corresponding regulon comprises the $a m t A$ and $a m t B$ genes, which encode ammonium transporters, as well as $g d h, g \ln A$ and $g l t B D$, which code for enzymes crucial for ammonium assimilation, i.e. glutamate dehydrogenase, glutamine synthetase and glutamate synthase. Furthermore, transcription of the $\operatorname{crnT}$ and $\operatorname{cod} A$ gene, responsible for creatinine transport and metabolism as well as the urt $A B C D E$ and ure $A B C E F G D$ operon, encoding a urea $\mathrm{ABC}$ transporter and urease, are controlled by AmtR in addition to a number of genes coding for biochemically uncharacterized enzymes and transport systems as well as signal transduction proteins.

In M. smegmatis transcription of amt1, encoding a putative ammonium permease, the $a m t B-g \ln K-g \ln D$ operon, which codes for an additional ammonium transporter and signal transduction proteins, as well as $g \ln A$, coding for glutamine synthetase, are positively controlled by $\operatorname{Gln} R$ [11]. Besides these genes encoding proteins for ammonium uptake and assimilation, the regulation of other genes and operons encoding various (putative) transporters of alternative nitrogen sources, e.g. narK, narK3, urtABCDE, as well as nitrogen assimilatory enzymes, e.g. $g d h, g \ln A 2$, $g \ln A 3, g \ln A 4$, gltBD, narIJHG, nirBD, ureABCFG, ureE$F A B C G D$, was unclear until now (for review, see $[1,12]$ ). Furthermore, $M$. smegmatis belongs to a group of Actinobacteria including e.g. Nocardia farcinica, Rhodococcus sp., Clavibacter michiganensis and Kineococcus radiotolerans that exhibit both, GlnR and AmtR. In none of these species, the function of AmtR and its interaction with GlnR have been addressed until now.

To expand our knowledge of nitrogen starvation response in M. smegmatis and to shed light on the function and interplay of GlnR and AmtR in this organism, DNA microarray analyses were carried out, with the aim to characterize the nitrogen control network of $M$. smegmatis in more detail.

\section{Results and discussion}

\section{Nitrogen starvation-dependent transcription of genes}

For a global analysis of nitrogen-starvation-induced genes, wild-type cells were grown up to the mid-exponential growth phase, when nitrogen starvation was induced by washing the cells and transferring them to minimal medium without nitrogen source. Total RNA was isolated after 0.5 hours of starvation and hybridized together with
RNA from untreated control cultures to DNA microarrays. As shown by Amon and co-workers [11], this procedure is sufficient for full induction of genes encoding ammonium transporters and high affinity ammonium assimilation enzymes. In response to the induction of nitrogen starvation, transcripts of 231 genes were found to be decreased and of 284 genes to be increased by at least a factor of 3 in the wild-type (Additional file 1: Table S1 and S2). These were classified according to functional categories [13].

COG classification of genes with decreased mRNA level (Figure 1A) revealed that $50 \%$ of these were allocated to the major group metabolism, another $27 \%$ to the major category poorly characterized. $16 \%$ of the genes with decreased transcript amounts in the wildtype under nitrogen starvation belonged to the group information storage and processing and 7\% correlated with the group cellular processes and signaling. Only 4\% of these 231 genes are described as putatively involved in nitrogen metabolism.

When the 284 genes with enhanced transcript levels upon starvation were analyzed, $12.5 \%$ were associated with nitrogen metabolism. Classification of these genes into COGs (Figure 1B) shows that $49 \%$ of these genes were poorly characterized, $37 \%$ belonged to the major category metabolism, $8 \%$ of the genes with enhanced transcript amounts in the wild-type under nitrogen starvation were allocated to information storage and processing, while the remaining $6 \%$ of genes belonged to cellular processes and signaling.

All in all, the microarray results indicated a general adaptation of $M$. smegmatis wild-type to the situation of growth arrest induced by nitrogen starvation. This includes not only nitrogen control, but influences other regulatory networks such as carbon and energy metabolism as well and a similar adaptation strategy was also shown previously for the closely related actinomycete C. glutamicum [14].

Transcriptome analyses of wild-type and glnR mutant strain In order to elucidate the specific nitrogen starvation response in more detail, the global transcription patterns of nitrogen-deprived wild-type and $\Delta g \ln R$ strain $\mathrm{MH} 1$ were compared. Transcripts of 125 genes were upregulated and of six genes down-regulated by at least a factor of 3 in the wild-type in comparison to MH1, when the two strains were starved for nitrogen. The classification of these genes into COGs (Figure 2) gave a first hint that GlnR is not only involved in the regulation of ammonium assimilation, which was further supported by a detailed inspection of the DNA microarray results (Table 1). Putative GlnR regulated genes included the genes amtB (msmeg_2425, $56 \mathrm{x}$ ), glnK (msmeg 2426, $53 \mathrm{x}), g \ln A$ (msmeg_4290, 34 x), $g \ln D$ (msmeg_2427, $18 \mathrm{x}$ ) 


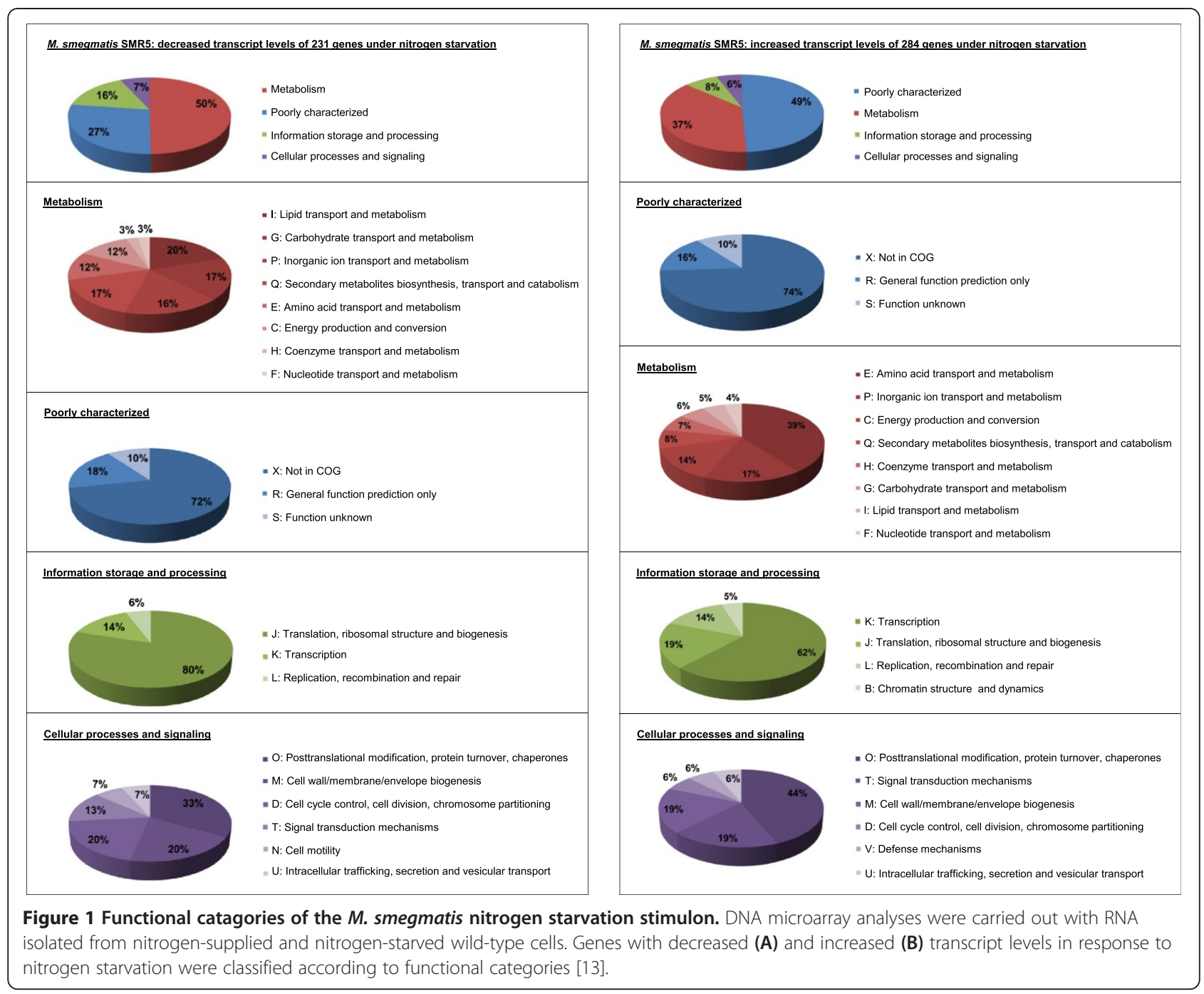

and amt1 (msmeg_6259, $12 \mathrm{x}$ ), which were described previously [11] besides others with obvious function in nitrogen metabolism. These include for example the nirBD gene cluster (msmeg_0427-0428) coding for nitrite reductase subunits, msmeg_0781, msmeg_1052, msmeg_2184 and msmeg_6735, encoding different putative permeases and transporter subunits involved in amino acid uptake, msmeg_1293, msmeg_2748, msmeg_4011, msmeg_5730 and msmeg_6660, encoding proteins putatively involved in purine and pyrimidine transport, as well as msmeg_2187, msmeg_2981 (urtB), msmeg_2982 (urtA) and msmeg 3626, encoding proteins for urea uptake and utilization. All in all, the results of transcriptome analyses of nitrogen-deprived wild-type and $\Delta g \ln R$ strain MH1 indicated a more global function of GlnR in the regulation of nitrogen metabolism. Similar results were obtained for S. coelicolor [3] and together indicate a more general role of GlnR in Actinobacteria.
The genes showing decreased transcript amounts (Table 2) had no obvious connection to nitrogen metabolism and were not further characterized. Four of these are encoding hypothetical proteins, two code for uncharacterized proteins with connection to hydrogenase expression.

\section{Validation of DNA microarray results}

The dependence of transcription changes of selected genes on the presence of GlnR was validated by RNA hybridization experiments (data not shown) and quantitative RT-PCR (qPCR; see Figure 3). For qPCR, the transcript of msmeg_3084 was used as internal control (Figure 3A). An increase of mRNA level in response to nitrogen starvation in the wild-type compared to $g \ln R$ deletion strain MH1 was verified for all targets tested, i.e. nirD, msmeg_0779, msmeg_1293, msmeg_2184, the $a m t B-g \ln K-g \ln D$ operon, msmeg_2522, msmeg_2526, 
SMR5 vs. MH1 -N: decreased transcript levels of 125 genes in the glnR deletion strain

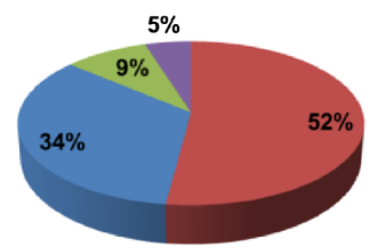

- Metabolism

- Poorly characterized

= Information storage and processing

- Cellular processes and signaling

\section{$\underline{\text { Metabolism }}$}

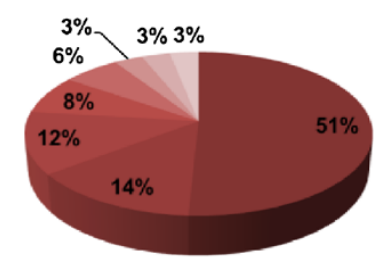

- E: Amino acid transport and metabolism

- C: Energy production and conversion

- $\mathrm{P}$ : Inorganic ion transport and metabolism

- F: Nucleotide transport and metabolism

- G: Carbohydrate transport and metabolism

= I: Lipid transport and metabolism

Q: Secondary metabolites biosynthesis, transport and catabolism

= $\mathrm{H}$ : Coenzyme transport and metabolism

\section{Poorly characterized}

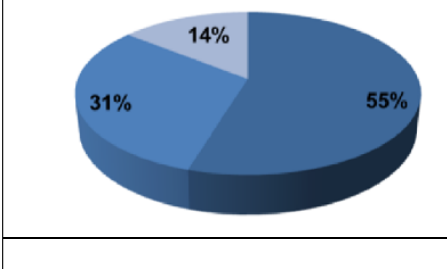

- X: Not in COG

- R: General function prediction only

II S: Function unknown

\section{Information storage and processing}

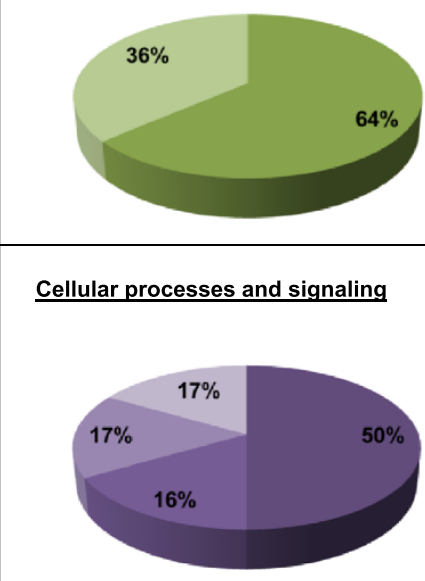

. K: Transcription

J: Translation, ribosomal structure and biogenesis

Figure 2 The GlnR modulon of $M$. smegmatis. DNA microarray analyses were carried out with RNA isolated from nitrogen-starved wild-type SMR5 and $g \ln R$ deletion strain MH1. Genes with decreased transcript levels in $g / n R$ deletion strain $\mathrm{MH} 1$ were classified according to functional categories [13].

urtA, msmeg_3400, glnA, glnA2, amtA, msmeg_5730, amt1, msmeg_6261 and msmeg_6816 (Figure 3B).

The real-time RT-PCR experiments validated the DNA microarray analyses; however, from the transcriptome analyses, no conclusion about direct or indirect influences of GlnR can be drawn, since for example changing metabolite concentrations might influence transcription patterns of genes. 
Table 1 Genes with increased mRNA amounts in the wild-type compared to gInR deletion strain MH1 in response to nitrogen starvation

\begin{tabular}{|c|c|c|}
\hline Gene identifier & Fold change & Annotation \\
\hline msmeg_3358 & 3.02 & YaeQ protein \\
\hline msmeg_4965 & 3.07 & Hypothetical protein \\
\hline msmeg_6507 & 3.07 & Glycogen debranching enyme GlgX ( $g \lg X)$ \\
\hline msmeg_1792 & 3.12 & Conserved hypothetical protein \\
\hline msmeg_4567 & 3.14 & Conserved hypothetical protein \\
\hline msmeg_4382 & 3.15 & Dehydrogenase-reductase SDR family member 10 \\
\hline msmeg_4011 & 3.26 & Putative pyrimidine permease RutG \\
\hline msmeg_2116 & 3.33 & PTS system, glucose-specific IIBC component \\
\hline msmeg_4570 & 3.34 & Conserved hypothetical protein \\
\hline msmeg_2187 & 3.36 & Urea amidolyase \\
\hline msmeg_4569 & 3.48 & Conserved hypothetical protein \\
\hline msmeg_1292 & 3.48 & FAD binding domain in molybdopterin dehydrogenase protein \\
\hline msmeg_4171 & 3.58 & Ribose transport system permease protein RbsC \\
\hline msmeg_3994 & 3.64 & Short chain dehydrogenase \\
\hline msmeg_5648 & 3.68 & Hypothetical protein \\
\hline msmeg_2189 & 3.68 & Allophanate hydrolase (atF) \\
\hline msmeg_0393 & 3.73 & Fmt protein \\
\hline msmeg_1153 & 3.73 & FAD dependent oxidoreductase \\
\hline msmeg_6659 & 3.74 & Hypothetical protein \\
\hline msmeg_6332 & 3.79 & Amino acid $A B C$ transporter, permease protein \\
\hline msmeg_3626 & 3.89 & Urease, beta subunit (ureB) \\
\hline msmeg_5083 & 4.00 & Conserved hypothetical protein \\
\hline msmeg_1152 & 4.01 & Citrate-proton symporter \\
\hline msmeg_5331 & 4.04 & UDP-glucoronosyl and UDP-glucosyl transferase family \\
\hline msmeg_1151 & 4.08 & DNA-binding protein \\
\hline msmeg_5783 & 4.10 & Acetyltransferase, GNAT family \\
\hline msmeg_1155 & 4.16 & Carnitinyl-CoA dehydratase \\
\hline msmeg_1157 & 4.17 & Short chain dehydrogenase \\
\hline msmeg_3912 & 4.20 & Acetoacetyl-CoA reductase \\
\hline msmeg_0565 & 4.33 & Putative glycosyl transferases group 1 \\
\hline msmeg_1184 & 4.40 & Serine esterase, cutinase family \\
\hline msmeg_1156 & 4.44 & Dihydrodipicolinate synthetase \\
\hline msmeg_1185 & 4.46 & Transcriptional regulator, AsnC family \\
\hline msmeg_1089 & 4.61 & Hypothetical protein \\
\hline msmeg_1088 & 4.63 & Glutamyl-tRNA(Gln)-aspartyl-tRNA(Asn) amidotransferase \\
\hline msmeg_0505 & 4.72 & Probable sugar $A B C$ transporter, substrate-binding protein \\
\hline msmeg_6880 & 4.92 & Hydrophobic amino acid $A B C$ transporter, putative \\
\hline msmeg_6879 & 4.97 & Nat permease for neutral amino acids NatD \\
\hline msmeg_3722 & 5.04 & Bifunctional coenyme PQQ synthesis protein C-D \\
\hline msmeg_1596 & 5.05 & Transcriptional regulator \\
\hline msmeg_6264 & 5.06 & Putative oxidoreductase \\
\hline msmeg_2523 & 5.11 & Efflux $A B C$ transporter, permease protein, putative \\
\hline msmeg_4381 & 5.14 & Amidase \\
\hline
\end{tabular}


Table 1 Genes with increased mRNA amounts in the wild-type compared to $g$ InR deletion strain MH1 in response to nitrogen starvation (Continued)

\begin{tabular}{|c|c|c|}
\hline msmeg_1090 & 5.24 & Amidase \\
\hline msmeg_1508 & 5.54 & Amino acid permease-associated region \\
\hline msmeg_5729 & 5.75 & Hydantoin racemase \\
\hline msmeg_6733 & 6.32 & Hydrolase, carbon-nitrogen family \\
\hline msmeg_2748 & 6.36 & Soluble pyridine nucleotide transhydrogenase (sthA) \\
\hline msmeg_1085 & 6.41 & Dipeptide transport system permease protein DppB \\
\hline msmeg_2569 & 6.61 & Oxidoreductase, 2OG-Fe(II) oxygenase family \\
\hline msmeg_0429 & 6.64 & Putative ferric uptake regulator \\
\hline msmeg_6878 & 6.97 & Inner-membrane translocator \\
\hline msmeg_6263 & 7.01 & Glutamate synthase family protein \\
\hline msmeg_6262 & 7.40 & FwdC-FmdC family protein \\
\hline msmeg_1295 & 7.42 & Transthyretin \\
\hline msmeg_3402 & 7.82 & Cytosine permease, putative \\
\hline msmeg_5356 & 8.15 & Hypothetical protein \\
\hline msmeg_1296 & 8.73 & Uricase \\
\hline msmeg_0780 & 8.79 & Phosphotransferase enyme family protein \\
\hline msmeg_6877 & 8.90 & Branched-chain amino acid transport system ATP-binding protein \\
\hline msmeg_0566 & 8.94 & Aliphatic amidase \\
\hline msmeg_3403 & 9.26 & Formamidase \\
\hline msmeg_1990 & 9.45 & Conserved hypothetical protein \\
\hline msmeg_1086 & 9.94 & $A B C$ transporter permease protein \\
\hline msmeg_0778 & 10.22 & Putative transcriptional regulator \\
\hline msmeg_6261 & 10.36 & Glutamine amidotransferase, class II \\
\hline msmeg_6660 & 10.75 & Permease, cytosine-purines, uracil, thiamine, allantoin family \\
\hline msmeg_6817 & 11.34 & RNA polymerase sigma factor, sigma-70 family \\
\hline msmeg_1052 & 11.63 & Amino acid carrier protein \\
\hline msmeg_6259 & 11.67 & Ammonium transporter (amt 1) \\
\hline msmeg_6881 & 11.75 & Transcriptional regulator, GntR family \\
\hline msmeg_2185 & 12.81 & Conserved hypothetical protein \\
\hline msmeg_2525 & 14.19 & Amino acid permease superfamily \\
\hline msmeg_1293 & 14.73 & Xanthine-uracil permeases family protein \\
\hline msmeg_2978 & 15.78 & ABC transporter ATP-binding protein \\
\hline msmeg_6260 & 16.11 & Glutamine synthetase, type III $(g \ln T)$ \\
\hline msmeg_4206 & 16.44 & Molybdopterin oxidoreductase \\
\hline msmeg_3400 & 17.66 & Glutamyl-tRNA(GIn) amidotransferase subunit A \\
\hline msmeg_0572 & 17.72 & Conserved hypothetical protein \\
\hline msmeg_2427 & 18.22 & Protein P-\|l uridylyltransferase $(g \ln D)$ \\
\hline msmeg_4637 & 18.43 & Conserved hypothetical protein \\
\hline msmeg_3401 & 18.68 & LamB-YCsF family protein \\
\hline msmeg_1988 & 18.75 & Conserved hypothetical protein \\
\hline msmeg_1597 & 18.80 & Transcription factor WhiB \\
\hline msmeg_2979 & 18.88 & ABC transporter ATP-binding protein \\
\hline msmeg_2981 & 19.17 & Branched-chain amino acid ABC-type transport system \\
\hline msmeg_6115 & 19.21 & Phosphoglycerate dehydrogenase \\
\hline
\end{tabular}


Table 1 Genes with increased mRNA amounts in the wild-type compared to gInR deletion strain MH1 in response to nitrogen starvation (Continued)

\begin{tabular}{|c|c|c|}
\hline msmeg_6735 & 19.26 & Amino acid permease, putative \\
\hline msmeg_1087 & 19.33 & Oligopeptide ABC transporter ATP-binding protein \\
\hline msmeg_6116 & 19.89 & Conserved hypothetical protein \\
\hline msmeg_5084 & 20.59 & Glycosyl transferase, group 2 family protein \\
\hline msmeg_5359 & 21.35 & Cyanate hydratase (cynS) \\
\hline msmeg_5360 & 22.01 & Formate-nitrate transporter \\
\hline msmeg_4501 & 22.33 & Sodium:dicarboxylate symporter \\
\hline msmeg_4635 & 22.90 & Ammonium transporter family protein \\
\hline msmeg_2980 & 23.33 & Putative membrane protein \\
\hline msmeg_2524 & 24.34 & ABC transporter, ATP-binding protein \\
\hline msmeg_2522 & 24.38 & Efflux $A B C$ transporter, permease protein \\
\hline msmeg_5358 & 25.10 & Acetamidase-Formamidase family \\
\hline msmeg_4294 & 26.01 & Glutamine synthetase, type I ( $g \ln A)$ \\
\hline msmeg_5765 & 29.55 & Globin \\
\hline msmeg_4638 & 30.14 & Vanillate O-demethylase oxidoreductase \\
\hline msmeg_4636 & 31.81 & Hypothetical protein \\
\hline msmeg_2186 & 32.35 & Conserved hypothetical protein \\
\hline msmeg_0570 & 32.58 & Conserved hypothetical protein \\
\hline msmeg_6816 & 33.03 & Molybdopterin oxidoreductase \\
\hline msmeg_0432 & 34.03 & Uroporphyrinogen-III synthetase \\
\hline msmeg_4290 & 34.13 & Glutamine synthetase, type I $(g \ln A)$ \\
\hline msmeg_0569 & 34.95 & Flavoprotein involved in $\mathrm{K}^{+}$transport \\
\hline msmeg_0779 & 35.16 & Short-chain dehydrogenase-reductase SDR \\
\hline msmeg_0781 & 36.20 & Amino acid permease \\
\hline msmeg_1987 & 42.51 & Conserved hypothetical protein \\
\hline msmeg_5730 & 45.31 & Permease for cytosine-purines, uracil, thiamine, allantoin \\
\hline msmeg_1082 & 47.68 & Putative response regulator \\
\hline msmeg_0571 & 48.04 & Hydrolase, carbon-nitrogen family \\
\hline msmeg_2184 & 48.27 & Amino acid permease \\
\hline msmeg_0428 & 48.97 & Nitrite reductase $[\mathrm{NAD}(\mathrm{P}) \mathrm{H}]$ small subunit (nirD) \\
\hline msmeg_2426 & 51.56 & Nitrogen regulatory protein P-II (glnK) \\
\hline msmeg_1084 & 51.81 & Peptide-opine-nickel uptake family $A B C$ transporter \\
\hline msmeg_0427 & 52.06 & Nitrite reductase $[\mathrm{NAD}(\mathrm{P}) \mathrm{H}]$, large subunit (nirB) \\
\hline msmeg_0433 & 54.53 & Nitrite extrusion protein \\
\hline msmeg_2425 & 56.21 & Ammonium transporter (amtB) \\
\hline msmeg_6734 & 62.84 & Dibenzothiophene desulfurization enzyme A \\
\hline msmeg_2526 & 66.62 & Copper methylamine oxidase \\
\hline msmeg_2982 & 136.17 & Putative periplasmic binding protein (urtA) \\
\hline
\end{tabular}

Binding of GlnR upstream of putative target genes

In order to test binding of GlnR to selected putative target DNAs, 200 to $300 \mathrm{bp}$ DNA fragments located upstream of different genes were amplified by PCR and used together with purified MBP-GlnR fusion protein in gel retardation experiments (Figure 4). Specific binding of
GlnR to the upstream DNA of msmeg_0572, msmeg_0781, msmeg_2184, amtB, msmeg_2526, urtA, msmeg_3400, $g \ln A, g \ln A 2$, $a m t A$ and $a m t 1$ was shown (Figure 4A).

Binding was not detected for the nirB, msmeg_1052, msmeg_1084, msmeg_1090, msmeg_1293, msmeg_2748, msmeg_2981, msmeg_4638, narK, msmeg_5734, glnR, 
Table 2 Genes with decreased mRNA amounts in the wild-type compared to $g / n R$ deletion strain in response to nitrogen starvation

\begin{tabular}{lll}
\hline Gene identifier & Fold change & Annotation \\
\hline msmeg_6498 & 3.96 & $\begin{array}{l}\text { Hypothetical protein } \\
\text { Hydrogenase assembly } \\
\text { chaperone HypC-HupF (hypC) }\end{array}$ \\
msmeg_2274 & 4.24 & $\begin{array}{l}\text { Hydrogenase expression-formation } \\
\text { protein HypD (hypD) }\end{array}$ \\
msmeg_1738 & 4.46 & $\begin{array}{l}\text { Probable conserved transmembrane } \\
\text { protein }\end{array}$ \\
msmeg_3680 & 4.61 & $\begin{array}{l}\text { Hypothetical protein } \\
\text { Hypothetical protein }\end{array}$ \\
msmeg_1999 & 10.08 &
\end{tabular}

msmeg_6258, msmeg_6734 and msmeg_6816 upstream region (Figure 4B). In these cases, longer DNA fragments spanning from 300 to $500 \mathrm{bps}$ of the respective upstream region were also tested; however, without positive result (data not shown).

To validate GlnR binding and to localize the GlnR binding site in more detail, a $220 \mathrm{bp}$ fragment upstream of $a m t B$ was chosen and competitive gel retardation assays were performed (Figure 5). When 50 bp overlapping DNA fragments covering the whole promoter sequence were added, fragments 1, 3, 7 and 8 did not lead to any inhibition of the DNA shift caused by GlnR binding. Addition of fragments 4, 5 and 6 led to strong inhibition, indicating that the GlnR binding site is located in this $100 \mathrm{bp}$ fragment. An additional weak binding site might exist in fragment 2 , as a very slight inhibition was also spotted here (Figure 5A and B).

To further specify the localization, the $50 \mathrm{bp}$ fragments 4 and 6 which caused inhibition of GlnR-binding to the 220 bp promoter fragment were used as digoxigenin-labeled DNA probes and 25 as well as $15 \mathrm{bp}$ DNA fragments were used as competitor DNA. While no inhibition of binding by the 25 bp fragments was observed for fragment 4 (data not shown) addition of fragment 6.1 inhibited GlnR-binding to fragment 6 (Figure $5 \mathrm{C}$ and $\mathrm{D}$ ). Thus, for $a m t B$, two binding sites were experimentally verified, one located $75-100$ bp upstream (fragment 6.1) and the other 100-150 bp upstream of the gene's start codon (fragment 4).

The binding sequences show similarity to the proposed binding motif [11]; however, for a more detailed characterization of GlnR binding sites in M. smegmatis, further analyses are necessary. Besides competitive gel retardation assays, especially ChIP and ChIP-chip analyses

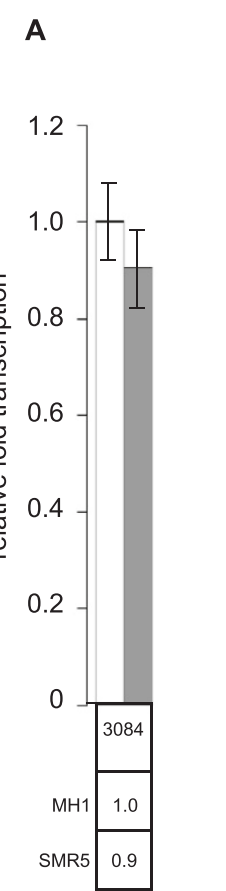

\section{B}

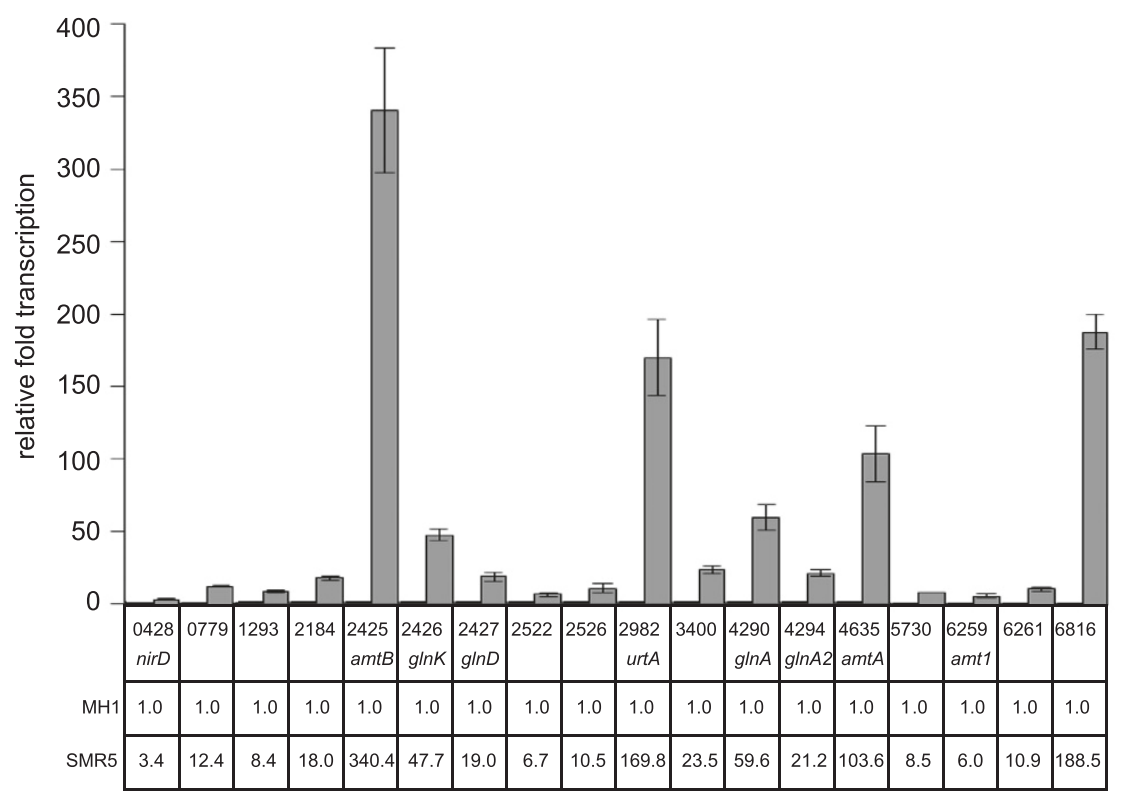

Figure 3 Verification of DNA affinity microarray results by quantitative RT-PCR. Total RNA of strains SMR5 and MH1 incubated for 30 min under nitrogen starvation was prepared and used as template for reverse transcription and PCR reaction. Specific primers were used for amplification of 100 bp fragments of target genes. (A) The gene msmeg_3084 was used as control; transcription of this housekeeping gene encoding glyceraldehyde-3-phosphate dehydrogenase was not significantly different in wild-type (grey bar) and glnR deletion strain (white bar). (B) Relative fold transcription of 20 target genes in the wild-type SMR5 was calculated (grey bars), while the transcription in the g/nR deletion strain was set one (white bars). Relative fold transcription was calculated in normalization to the reference gene msmeg_3084. Genes are sorted according to their msmeg numbers. 
A
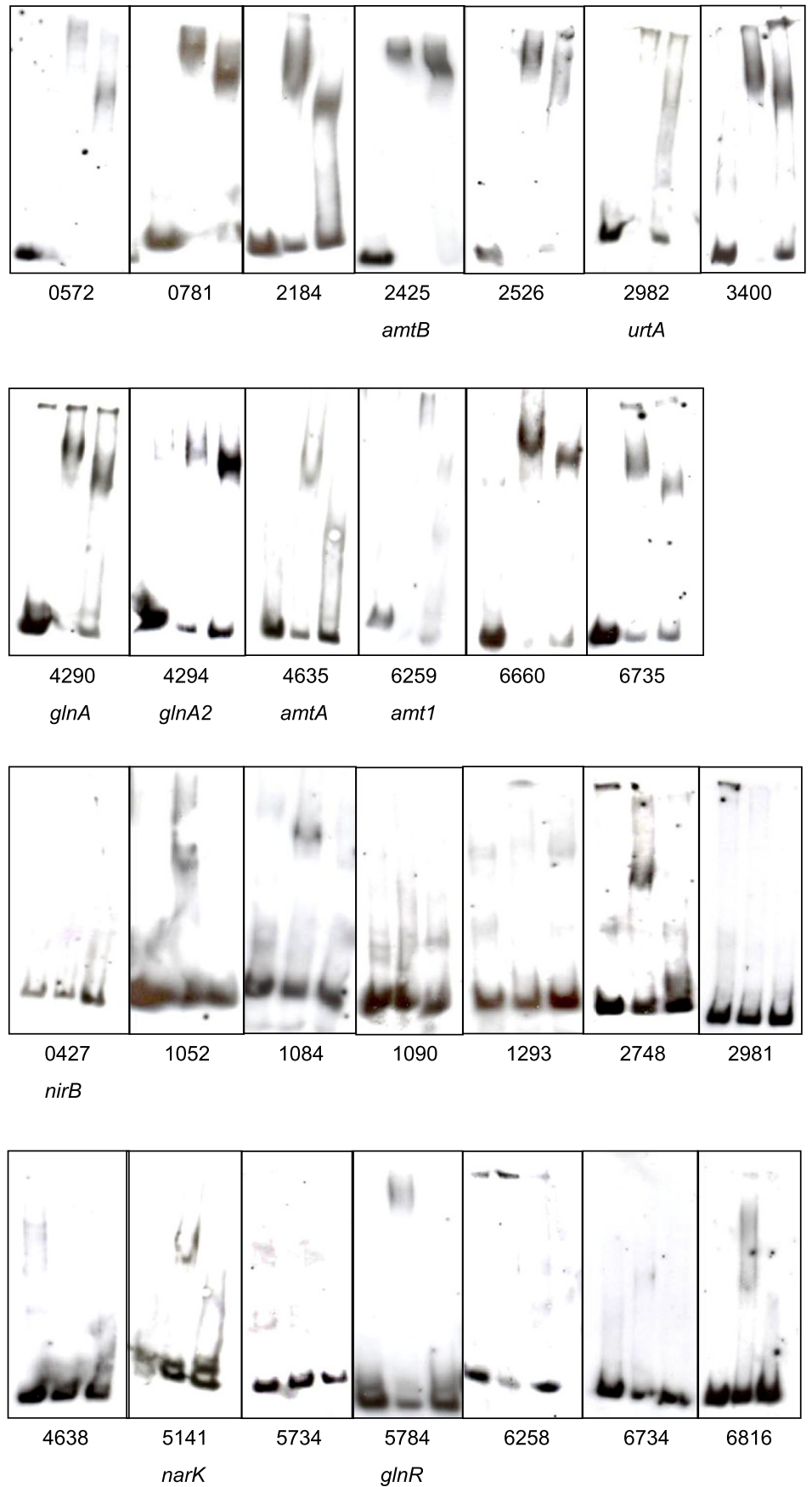

Figure 4 Test of GlnR binding by gel retardation assays. 200-300 bp DNA fragments upstream of GlnR target genes labeled with digoxigenin were used. For each gene free DNA (lane 1), DNA plus 400 ng MBP-GInR (lane 2) and DNA plus 400 ng MBP-GInR plus $3 \mu \mathrm{g}$ competitor DNA polyd[I-C] (lane 3) was tested. (A) Target genes with specific binding; (B) unspecific or no binding.

as presented recently for S. venezuelae [15] might be carried out.

\section{Growth of M. smegmatis on different nitrogen sources} Deduced from the increased transcript levels of several genes in the wild-type compared to $\Delta g \ln R$ strain MH1
(Table 1), a number of new substances were proposed as nitrogen sources for M. smegmatis. For ammonium, alanine, asparagine, glutamic acid, glutamine, nitrate, nitrite and urea a function as nitrogen source was already shown [16-18]; however, due to the experimental set-up, the experiments carried out here allowed conclusions 


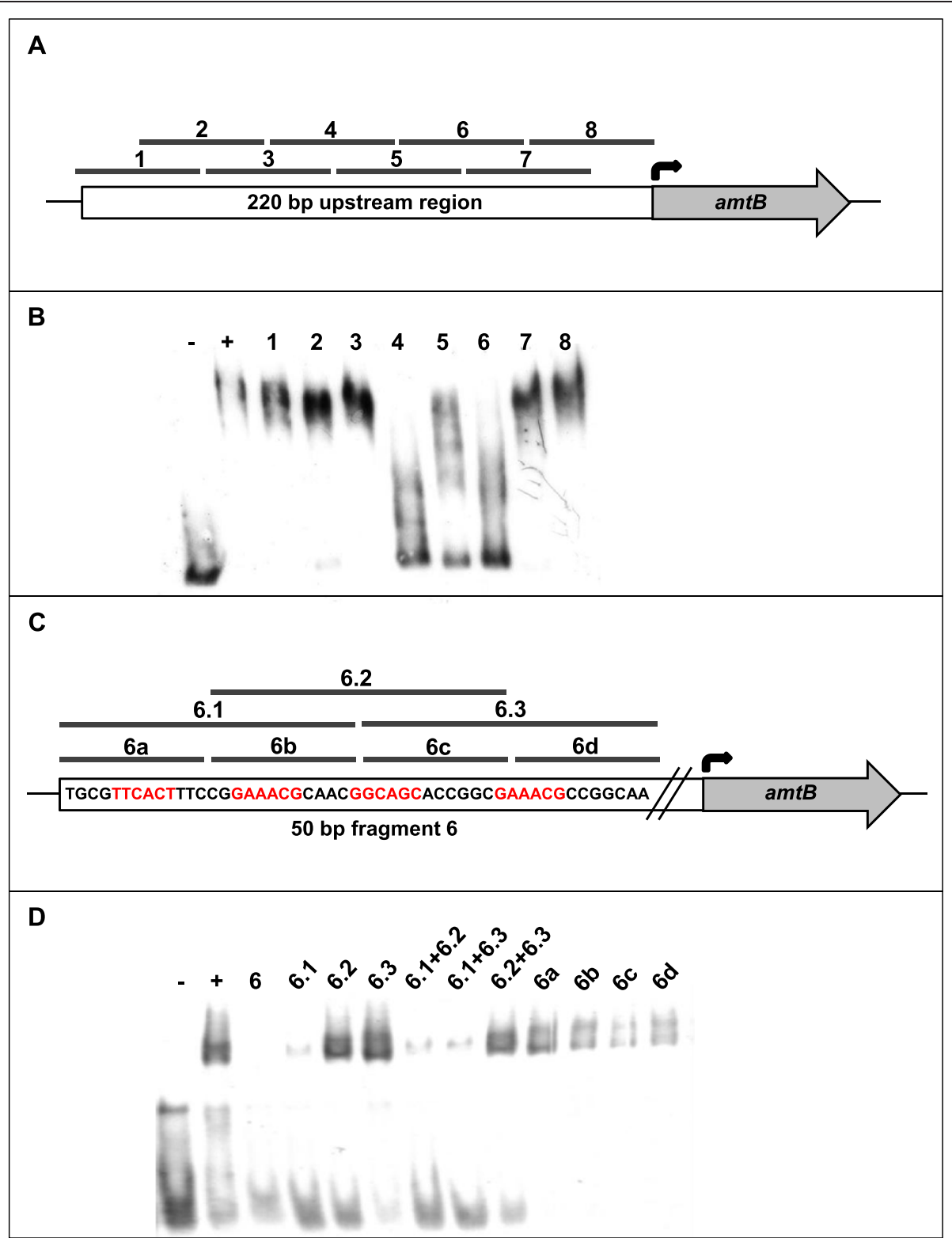

Figure 5 Competitive gel retardation experiment. (A) Model of eight overlapping 50 bp DNA fragments covering the 220 bp upstream region of $a m t B$. (B). When each of these fragments was added in 1000-fold surplus to gel retardation samples consisting of 220 bp digoxigenin-labeled $a m t B$ promoter fragment and purified MBP-GInR, an inhibition of the shift was spotted for fragments 4, 5, 6 and weakly 2. (C) Model of three overlapping 25 bp DNA fragments (6.1-6.3) and four 15 bp fragments (6a-d) covering the 50 bp fragment 6 in the upstream region of amtB. (D) Addition of these fragments in 1,000-fold surplus to gel retardation samples containing 50 bp digoxigenin-labeled fragment 6 and 600 ng MBP-GlnR each. An inhibition of the shift was detected for fragment 6.1. -: free DNA as negative control. +: DNA plus 600 ng MBP-GlnR as positive control.

about the GlnR-dependent or -independent regulation of assimilation pathways.

Growth experiments were carried out using the various substances tested as sole nitrogen source and comparing wild-type and $\Delta g \ln R$ strain MH1 (Figure 6). 7H9 medium was used as positive control and nitrogen-free 7H9 (7H9-N) as negative control. Standard 7H9 medium contains ammonium sulphate, ferric ammonium citrate and glutamic acid as nitrogen sources. When ammonium sulphate and ferric ammonium citrate were tested alone, a reduced growth rate and final $\mathrm{OD}_{600}$ was observed, independently from the presence or absence of GlnR, reflecting that ammonium $\left(\mathrm{NH}_{4}^{+}\right)$is membranepermeable in its unprotonated form ammonia $\left(\mathrm{NH}_{3}\right)$ and that under the growth conditions tested, ammonium was not limiting. 


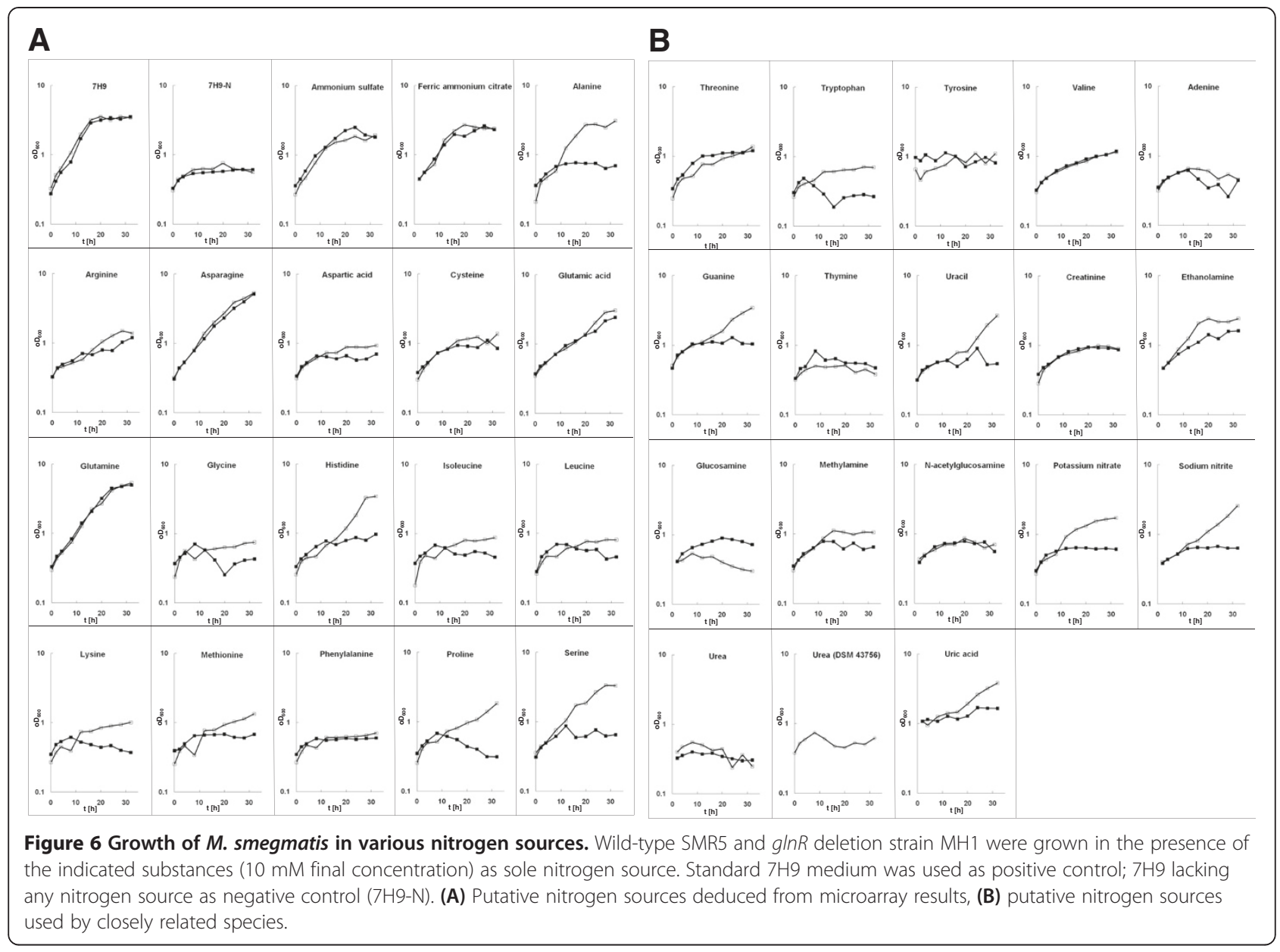

Further growth tests revealed that metabolism of alanine, histidine, proline and serine was significantly impaired in strain MH1 compared to the wild-type. Consequently, uptake and/or metabolism of these amino acids seem to be directly or indirectly regulated by GlnR. No significant influence of a $g \ln R$ deletion was observed when arginine, asparagine, glutamate, glutamine and valine were used as sole nitrogen source, indicating a GlnRindependent regulation of the metabolism of these amino acids. Aspartate, cysteine, glycine isoleucine, leucine, lysine, methionine, phenylalanine, threonine, tryptophan and tyrosine are poor or not suitable nitrogen sources for $M$. smegmatis under the conditions tested here (Figure 6A).

The increased levels of various genes connected to purine and pyrimidine uptake and metabolism (Table 1) in response to nitrogen starvation prompted us to test these also as nitrogen sources. Guanine and uracil supported growth in a GlnR-dependent manner, which is in accordance with increased mRNA levels for (msmeg_5730 $45 \mathrm{x}$, msmeg_129315 x, msmeg_666011 x, encoding putative uracil transport proteins; Table 1), while adenine and thymine were no suitable nitrogen sources.
Additionally other substrates, which are for example used by corynebacteria or streptomycetes, were tested (Figure 6B). GlnR-dependent growth was observed when ethanolamine, nitrate, nitrite or uric acid were added, which is in accordance with the transcriptome data. Growth was not supported by creatinine, glucosamine, methylamine, $\mathrm{N}$-acetylglucosamine and urea. The latter finding was especially puzzling, since M. smegmatis is characterized as urease-positive and gene clusters for two ureases and one urea transporter were described based on bioinformatic analyses [12]. Furthermore, when transcript patterns of nitrogen-supplied and -starved wild-type cells were compared in this study, increased mRNA levels were observed at least for one gene of a putative urt (urea transporter) gene cluster (msmeg_2982 $136 \mathrm{x}$ ) and for a putative urea ammonium lyase (msmeg_2187 $3 \mathrm{x}$ ). To exclude strain-specific variations, type-strain DSM 43796 (equivalent to ATCC 19420 and NCTC 8159) was tested under the same growth conditions as SMR5 and MH1. Also in this case, supply of urea alone did not support growth in 7H9-N independent of the addition for example of different trace element solutions (data not shown). Subsequently carried out 
enzyme activity measurements revealed a urease activity of $1 \mu \mathrm{mol}$ of ammonium released $\mathrm{min}^{-1}$ (mg protein) ${ }^{-1}$, independent of growth of strains SMR5 and DSM 43756 in nitrogen surplus or incubated for 30 minutes under nitrogen starvation. This correlates with data obtained for C. glutamicum, which shows a urease activity of $0.9 \mu \mathrm{mol} \mathrm{min}^{-1}$ (mg protein) ${ }^{-1}$ in complex medium and a urease activity of $0.9-2.2 \mu \mathrm{mol} \mathrm{m^{-1 }}$ (mg protein) $)^{-1}$ when ammonium is used as single nitrogen source. In this bacterium, however, urease activity is increased to $7.8 \mu \mathrm{mol} \mathrm{min}^{-1}$ (mg protein) $)^{-1}$, when cells are exposed to nitrogen starvation $[19,20]$. Despite the fact that urease activity is not upregulated in response to starvation, $M$. smegmatis shows at least low urease activity and the reason for the complete growth deficiency with urea as single nitrogen source remains unclear.

In summary, as a soil bacterium and opportunistic human pathogen, $M$. smegmatis is able to metabolize a wide variety of nitrogen sources. Transcriptome and growth data presented here hint to a major role of GlnR in ammonium, amino acid, nitrate/nitrite and purine/ pyrimidine assimilation, while additionally other regulators seem to be present as well as indicated by the GlnR-independent metabolism of several amino acids as nitrogen sources.

\section{Analysis of the AmtR regulon}

The experiments described above supported the idea that GlnR is a major nitrogen regulator in M. smegmatis, which consequently leads to the question of AmtR function in this organism. In a first approach to characterize the AmtR regulon, a bioinformatic analysis was carried out to identify AmtR-controlled genes in M. smegmatis. For this purpose, a co-occurrence analysis was carried out using the genome information of ten actinobacterial genomes, i.e. Arthrobacter aurescens, C. michiganensis, C. efficiens, Gordonia bronchialis, K. radiotolerans, M. smegmatis, Nocardia farcinica, Rhodococcus jostii, Streptomyces avermitilis and Tsukumurella paurometabola. From these genomes, one conserved operon was extracted, which (i) shows a high degree of co-occurrence with the $a m t R$ gene, (ii) shows co-localization with amtR in $A$. aurescens, Rhodococcus sp. RHA1 and S. avermitilis and (iii) seems to be involved in nitrogen metabolism based on their annotation (Table 3). K. radiotolerans features the most condensed AmtR gene cluster (Figure 7); all open reading frames of this putative operon feature overlapping start and stop codons (GTGA or ATGA). While AmtR and the amino acid permease are highly conserved and well consistently annotated in the different genomes, the exact functions of unknown reading frames urf1 and urf2, the urea carboxylase and the amidase are highly speculative and deduced from annotations (automatic and manual), domain analyses and PFAM searches. The location of these unknown reading frames in direct genomic neighborhood to the putative urea carboxylase-encoding gene is highly conserved in all investigated genomes, while the locations of the genes coding for amino acid permease and the amidase are more variable. Particularly the $a m t R$ gene can be found in close vicinity as well as completely elsewhere in the respective genome sequences (Table 3, Figure 7).

At least four of the identified six putatively AmtRregulated $M$. smegmatis genes showed increased transcript levels in response to starvation in the wild-type and seem to be under control of GlnR (msmeg_2184 48 $\mathrm{x}$, msmeg_2185 $13 \mathrm{x}$, msmeg_2186 $32 \mathrm{x}$, msmg_2187 $3 \mathrm{x}$, msmg_2189 $4 \mathrm{x}$; Table 2). To investigate transcription control of these genes, a strain, designated YL1, with in frame deletion of gene fragment $\left(a m t R_{D B D}\right)$ encoding the DNA binding domain of AmtR and an $a m t R_{D B D} /$ $g \ln R$ double deletion strain, designated YL2, were constructed, respectively. These strains were analyzed in respect to nitrogen-starvation-dependent transcription.

RNA hybridization experiments with RNA isolated from the wild-type and amtR deletion strain YL1, isolated from nitrogen-supplied cells and after different intervals of nitrogen starvation showed significantly stronger signals for the proposed AmtR-regulated genes msmeg_2184 (Figure 8A), msmeg_2187 and msmeg_2189 (data not shown) in the mutant; however, nitrogen control was still intact. Wild-type regulation for all genes was restored by a plasmid carrying $a m t R$, while the vector alone did not complement the deletion (see Figure 8B for msmeg 2184, others: data not shown). Nitrogendependent regulation of AmtR-regulated genes was abolished in $g \ln R$ deletion strain MH1 (see Figure 8C msmeg 2184, others: data not shown), indicating that AmtR is a secondary regulator of the master regulator GlnR. This model is in accordance with the transcriptome analyses presented above (Table 1).

To verify direct AmtR-DNA interaction, M. smegmatis AmtR was overexpressed in Eschericha coli, purified and applied in gel retardation experiments. Binding of AmtR was tested for upstream DNA of msmeg 2184 and binding to the msmeg_2184 upstream region was demonstrated (Figure 9). Since TetR-type regulators often bind small effector molecules that induce release of the repressor from its binding site, addition of putative AmtR effectors deduced from the putative function of target genes, i.e. urea and different amino acids, were tested in various concentrations ( 0.5 to $5 \mathrm{mM}$ ) but had no influence on binding to the msmeg_2184 upstream region (data not shown).

For a more global analysis of the AmtR regulon, DNA microarray experiments were carried out. RNA samples isolated from the wild-type and amtR deletion strain YL1 grown under nitrogen limitation were 
Table 3 Distribution of AmtR and screening for AmtR-regulated genes

\begin{tabular}{|c|c|c|c|c|}
\hline \multirow[t]{2}{*}{ Organism (Reference) } & \multicolumn{4}{|c|}{ Putative function and gene identifier } \\
\hline & $\begin{array}{l}\text { Amino acid } \\
\text { permease }\end{array}$ & $\begin{array}{l}\text { Urea } \\
\text { carboxylase }\end{array}$ & Amidase & AmtR \\
\hline Arthrobacter aurescens TC1 [21] & AAur_0190 & AAur_0187 & AAur_0186 & AAur0192 \\
\hline Corynebacterium efficiens YS-314 [22] & ce0711 & ce0713 & ce0710 & се0939 \\
\hline Clavibacter michi-ganensis NCPPB 382 [23] & CMM_0123 & CMM_0120 & CMM_2824 & CMM_0119 \\
\hline Gordonia bronchialis DSM 43247 (NCBI GenBank, acc. no. CP001802.1) & Gbro_3891 & Gbro_3888 & Gbro_3887 & Gbro_0881 \\
\hline Kineococcus radiotolerans SRS30216 [24] & Krad_0901 & Krad_0904 & Krad_0905 & Krad_0906 \\
\hline Mycobacterium smegmatis mc 155 (NCBI GenBank, acc. no. CP000480) & msmeg_2184 & msmeg_2187 & msmeg_2189 & msmeg_4300 \\
\hline Nocardia farcinica IFM10152 [25] & nfa22220 & nfa22190 & nfa22180 & nfa22230 \\
\hline Rhodococcus jostii RHA1 (NCBI GenBank, acc. no. CP000431.1) & RHA1_ro06919 & RHA1_ro06922 & RHA1_ro02136 & RHA1_ro06918 \\
\hline Streptomyces avermitilis MA-4680 [26] & sav6709 & sav6698 & sav6697 & sav6701 \\
\hline $\begin{array}{l}\text { Tsukamurella paurometabola DSM20162 (NCBI GenBank, acc. no. } \\
\text { CP001966) }\end{array}$ & Tpau_1591 & Tpau_1594 & Tpau_1595 & Tpau_1590 \\
\hline
\end{tabular}

The genome sequences of various Actinobacteria were screened for an amtR gene and co-occurrence of putatively AmtR-regulated genes (hypothetical urea carboxylase-associated unknown reading frames not shown, for details see text).

A

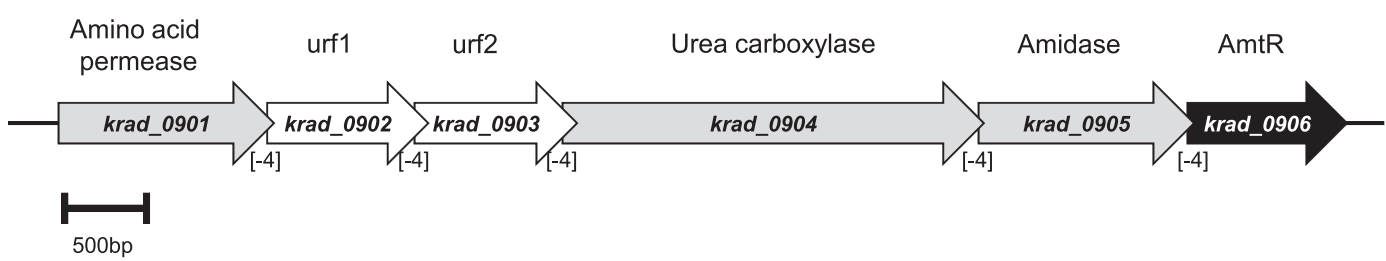

B

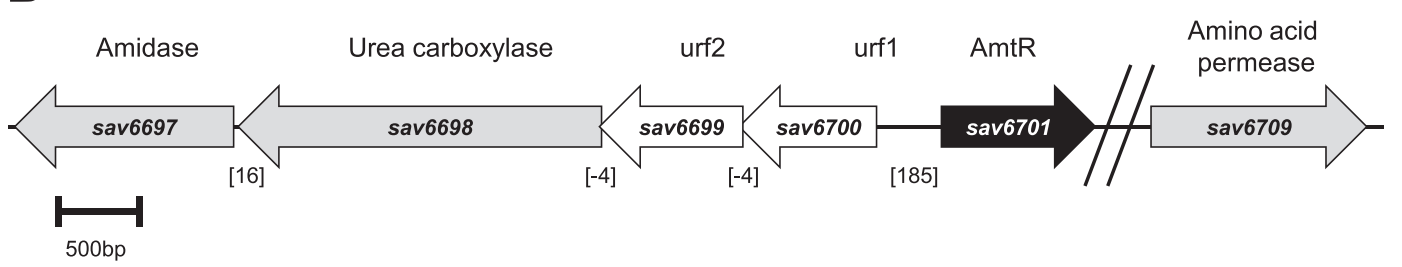

C

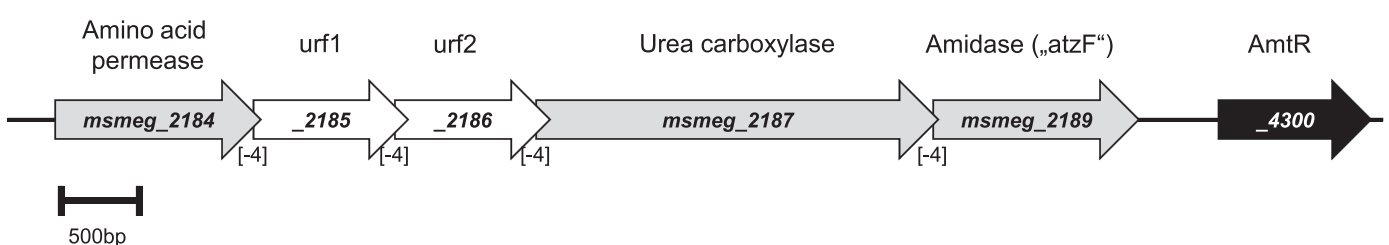

Figure 7 Co-occurrence of amtR and AmtR-regulated genes in selected Actinobacteria. Genomic map of the highly conserved AmtR operon in $K$. radiotolerans (A), S. avermitilis (B) and M. smegmatis (C). The arrows indicate length and transcriptional orientation of annotated genes which are depicted by the respective orf number. Numbers in square brackets show the lengths of intergenic regions in bp. While the putative $K$. radiotolerans operon shows a subsequent series of genes with overlapping reading frames, the amtR gene is transcribed in opposite direction in S. avermitilis and the amino acid permease-encoding gene is located elsewhere, while in $M$. smegmatis, the amtR gene is not co-localized with the putatively AmtR-regulated genes (see Table 3 for details). 


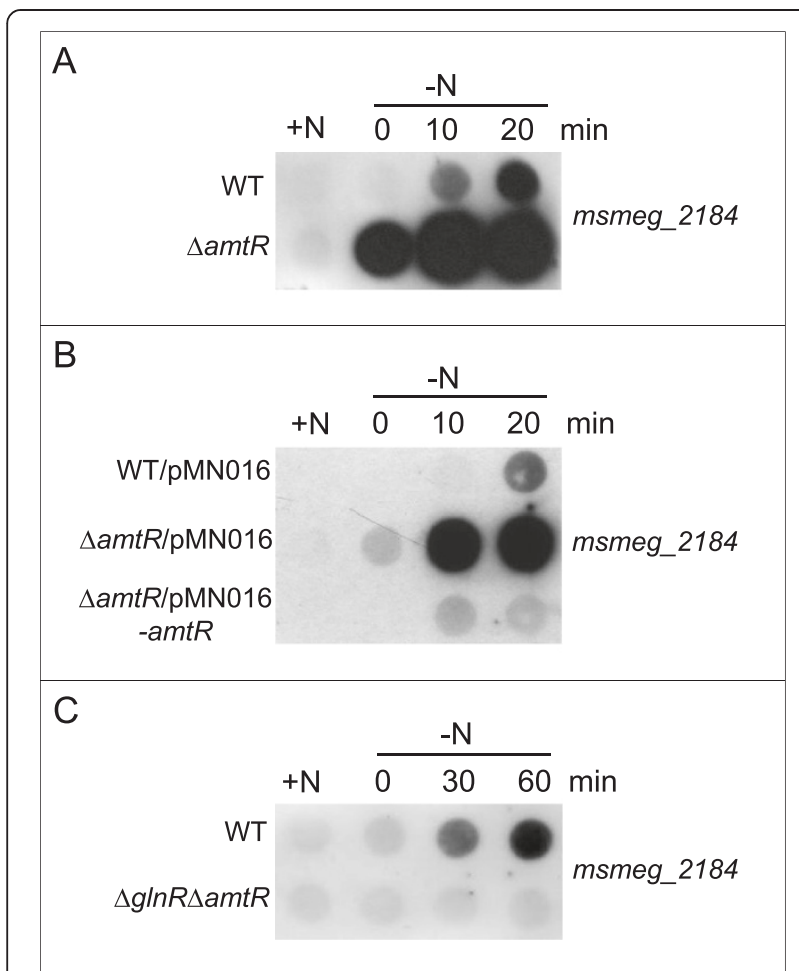

Figure 8 Influence of AmtR on target gene expression. Hybridization experiments were carried out with RNA isolated from nitrogen-supplied cells and after different intervals of nitrogen starvation and a probe specific for msmeg_2184 mRNA. (A) Comparison of wild-type SMR5 (WT) and amtR deletion strain YL1 ( $\triangle a m t R)$. (B) Complementation of amtR deletion strain YL1 with plasmid pMN016-amtR ( $\triangle a m t R / p M N 016-a m t R$ ); wild-type and strain YL1 transformed with vector pMN016 (WT/pMN016 and $\triangle a m t R / p M N 016)$ were used as control. (C) Influence of a glnR/amtR double deletion ( $\triangle g \ln R \triangle a m t R)$.

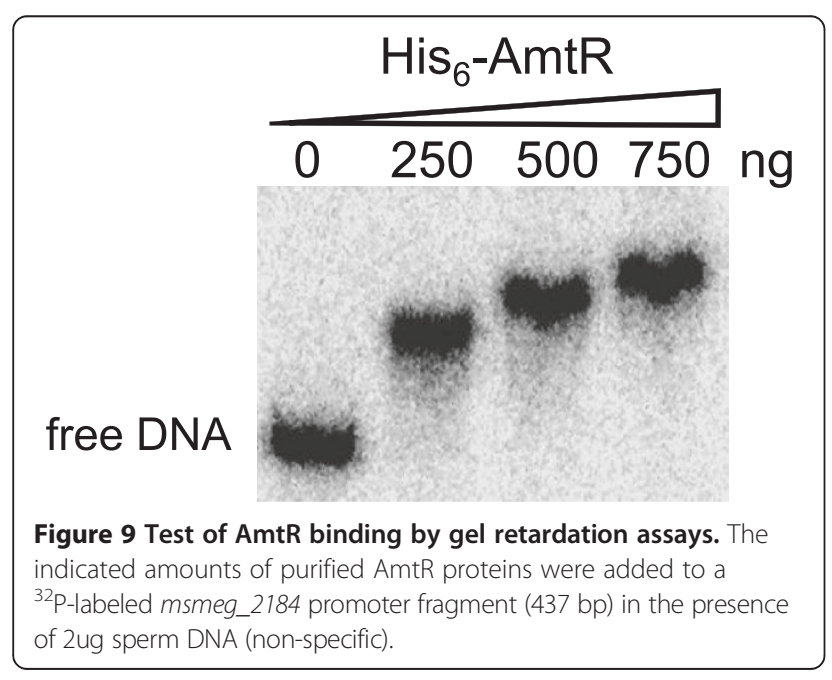

hybridized, and also RNA samples from $a m t R$ deletion mutant YL1 grown with and without nitrogen source were analyzed. No further AmtR targets were observed (data not shown), indicating that AmtR controls only a very small regulon, which is part of the GlnR modulon in M. smegmatis.

In an additional approach, autoregulation of AmtR was analyzed. This regulatory mechanism typical for TetR-type regulators [27] was in fact observed (Figure 10). Since the $a m t R$ deletion only comprised the part of the gene encoding the DNA binding domain, an $a m t R$ target was detectable, which was stronger in the deletion mutant YL1 compared to the wild-type (Figure 10A). Induction of nitrogen starvation or an additional deletion of $g \ln R$ (Figure 10B) had no effect, indication a nitrogen-independent regulation of AmtR expression.

\section{Conclusions}

Deprivation of nitrogen leads to growth arrest in $M$. smegmatis and induces not only specific transcriptional alterations in respect to genes encoding nitrogenrelated proteins, but a general starvation response at the transcriptional level. This includes changes in the mRNA levels of several hundred genes encoding transporters, proteins involved in nitrogen metabolism and regulation, energy generation and protein turnover etc. and was for example also observed in other Actinobacteria such as C. glutamicum $[14,28]$.

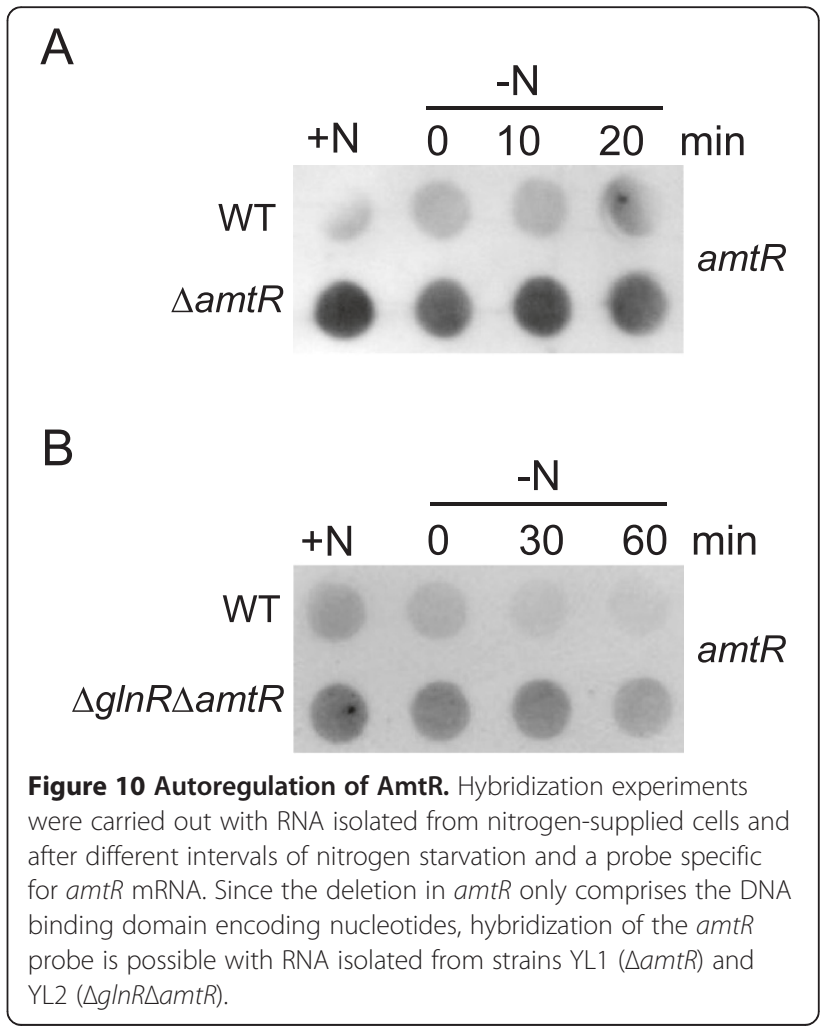


Based on the DNA microarray data obtained for M. smegmatis wild-type SMR5 and $g \ln R$ mutant MH1 and growth experiments, GlnR seems to play a crucial role in nitrogen metabolism in $M$. smegmatis., including the uptake and assimilation of ammonium, different amino acids (alanine, histidine, proline, serine), nitrate, nitrite, uric acid, ethanolamine, guanine and uracil, while, AmtR, the master regulator of nitrogen control in corynebacteria plays a minor role. All in all, nitrogen control in this species resembles carbon catabolite repression (CCR) in enterobacteria (for recent reviews on CCR in bacteria, see $[29,30]$. Like CcpA in CCR, GlnR seems to be the global regulator and functions as an activator in response to a starvation stimulus, while AmtR is a specific repressor of a small regulon, corresponding to LacI in CCR.

In addition to the GlnR-dependent regulation of nitrogen metabolism, genes not associated with nitrogen were indicated as putative GlnR targets by the DNA microarray analyses carried out. While these genes were not in the focus of this study, it can be assumed that the regulatory function of GlnR might not be restricted to nitrogen metabolism in $M$. smegmatis. This has also been suggested in similar studies focusing on S. coelicolor GlnR [3], where genes involved in carbon metabolism, stress response and antibiotic biosynthesis were also found to be GlnR-controlled confirming the regulatory function of GlnR beyond nitrogen metabolism. Future work will concentrate on the question, whether the observed transcription changes of non-nitrogen-related genes are directly GlnR-regulated or the result of perturbations caused by the $g \ln R$ deletion, which indirectly affect expression.

\section{Methods}

\section{Bioinformatics analyses}

For bioinformatics analysis of the AmtR regulon, a screening and co-occurrence approach was carried out. Genome sequences were obtained from the NCBI Genbank (ftp://ftp.ncbi.nih.gov/genbank/genomes/Bacteria/) and manually investigated with the software program Artemis (Sanger Institute). Homology analyses were performed with the microbial genomes BLAST databases at the NCBI and JCVI CMR servers. Advanced protein sequence predictions were done at the EMBL SMART domain analysis server and co-occurrence screenings were performed with the EMBL STRING interaction networks database.

\section{Growth conditions}

Bacteria were routinely grown at $37^{\circ} \mathrm{C}$ in baffled flasks under agitation. Mycobacterial strains were grown in Middlebrook 7H9 liquid medium (Difco Laboratories; per $900 \mathrm{ml}$ approx. $0.5 \mathrm{~g}$ ammonium sulfate, $0.5 \mathrm{~g} \mathrm{~L}$-glutamic acid, $0.1 \mathrm{~g}$ sodium citrate, $1.0 \mathrm{mg}$ pyridoxine, $0.5 \mathrm{mg}$ biotin,
$2.5 \mathrm{~g}$ disodium phosphate, $1.0 \mathrm{~g}$ mono potassium phosphate, $0.04 \mathrm{~g}$ ferric ammonium citrate, $0.05 \mathrm{~g}$ magnesium sulfate, $0.5 \mathrm{mg}$ calcium chloride, $1.0 \mathrm{mg}$ zinc sulfate, $1.0 \mathrm{mg}$ copper sulfate), supplemented with $0.2 \%$ glycerol and $0.05 \%$ Tween 80 or on Middlebrook 7H9 medium (Difco Laboratories) with $1.5 \%$ agar supplemented with $0.2 \%$ glycerol and $0.05 \%$ Tween 80 . If appropriate, antibiotics were added in the following concentrations: hygromycin $\left(200 \mu \mathrm{g} \mathrm{ml}^{-1}\right.$ for E. coli; $50 \mu \mathrm{g} \mathrm{ml}^{-1}$ for M. smegmatis), kanamycin (30 $\mu \mathrm{g} \mathrm{ml}^{-1}$ for E. coli; $10 \mu \mathrm{g} \mathrm{ml}^{-1}$ for M. smegmatis) and streptomycin $\left(400 \mu \mathrm{g} \mathrm{ml}^{-1}\right.$ for M. smegmatis). In order to study the effects of nitrogen starvation, a fresh M. smegmatis culture was used to inoculate $7 \mathrm{H} 9$ medium for overnight growth. This culture, with an overnight $\mathrm{OD}_{600}$ of approximately three to four, was used to inoculate fresh $7 \mathrm{H} 9$ medium to an $\mathrm{OD}_{600}$ of approximately 0.2 , and cells were grown for 10 to 11 hours until the exponential growth phase was reached $\left(\mathrm{OD}_{600}\right.$ approximately 0.6 to 0.8 ). To induce nitrogen starvation, cells were harvested by centrifugation, washed and resuspended in pre-warmed $7 \mathrm{H} 9$ medium without nitrogen source $(7 \mathrm{H} 9$ lacking ammonium sulfate and glutamic acid and containing iron citrate instead of iron ammonium citrate). For control, the unstarved cells were harvested, washed, and transferred using 7H9 medium.

\section{General molecular biology techniques}

For plasmid isolation, transformation, and cloning standard techniques were used [31]. E. coli strain DH5 $\alpha$ MCR [32] was used as cloning host. Plasmids were subsequently brought into competent $M$. smegmatis cells by electroporation. Chromosomal DNA was extracted from $100 \mathrm{ml}$ cultures grown to stationary phase as described [33]. DNA sequence analyses were carried out using Big Dye ${ }^{\circ}$ Terminator V3.1 Cycle Sequencing kit (Perkin Elmer).

\section{Construction of an amtR deletion strain}

To inactivate the AmtR function, a mutant with in-frame deletion of the DNA fragment $\left(a m t R_{D B D}\right)$ encoding AmtR DNA-binding domain (DBD) (amino acid residue 26 to 72) was generated as described earlier [11]. Briefly, two DNA fragments ( $1 \mathrm{~kb}$ up- and downstream of $\left.a m t R_{D B D}\right)$ were amplified via PCR using chromosomal DNA from M. smegmatis strain SMR5 as a template. SwaI and PacI restriction sites were introduced into the primer sequences used for amplification of the upstream arm and SpeI and PmeI sites into the primer sequences used for amplification of the downstream arm (Additional file 1: Table S3). The PCR products were then cloned in vector pML814 (ColE1 origin, FRT-hyg-FRT, rpsL, Amp ${ }^{\mathrm{R}}, \mathrm{Hyg}^{\mathrm{R}}$, $6220 \mathrm{bp}$, general deletion vector), resulting in the recombinant plasmid pML814 $\triangle a m t R_{D B D}$, which carried a $F R T$ hyg-FRT expression cassette [34] flanked by the upstream 
and downstream arms. M. smegmatis SMR5 was transformed with pML814 $\triangle a m t R_{D B D}$ and the transformants were first selected on hygromycin-containing plates to obtain single crossovers [34]. After verification of the single crossover event via colony PCR, cells were further selected on hygromycin/streptomycin containing plates. Clones on these plates should have lost the vector and have the integrated FRT-hyg-FRT cassette in the chromosome. After verification of the double crossover event via PCR, the FLP recombinase was used to specifically remove the hyg gene from the chromosome, thus generating a marker-free deletion mutant. Selection of clones was performed using hygromycin/streptomycin-containing plates. Deletion of $a m t R_{D B D}$ in the resulting strain $\mathrm{MH} 2$ was verified by PCR and Southern blotting (data not shown).

On basis of the mutant strain YL1, $g \ln R$ was further deleted as described earlier [11], generating the mutant strain YL2, with the inactivation of both $a m t R_{D B D}$ and $g \ln R$, which was confirmed by PCR and Southern blotting (data not shown).

\section{Construction of amtR carrying plasmids}

For complementation assays, the $a m t R$ gene was amplified by PCR using chromosomal DNA of $M$. smegmatis as template and the primers amtRcom-fw/amtRcom-rev (see Additional file 1: Table S3). The PCR products were ligated to plasmid pMN016 ( $\mathrm{p}_{\text {smyc }}-m s p A$, ColE1 origin, pAL5000 origin, $\mathrm{Hyg}^{\mathrm{R}}, 6164 \mathrm{bp}$, [35]) between the SwaI and PacI sites. For the overexpression of AmtR protein in E. coli, the amtR gene was amplified by PCR (for primers, see Additional file 1: Table S3) and ligated to plasmid pQE70 (Qiagen, Hilden) to add a C-terminal $\mathrm{His}_{6}$-tag to the expressed protein, leading to plasmid pQE-amtR-His . $_{\text {. }}$ The resulting plasmids pMN016-amtR and pQE-amtR-His were sequenced for verification (data not shown).

\section{Construction of antisense probes}

For the generation of antisense probes, internal DNA fragments of the corresponding genes were amplified by PCR (primers for the different probes are listed in supplementary materials, Additional file 1: Table S3). The reverse primers encoded the promoter region for $\mathrm{T} 7$ polymerase, which allowed in vitro transcription of probes using $\mathrm{T} 7$ polymerase.

\section{RNA preparation, hybridization analyses}

M. smegmatis RNA was prepared from $6 \mathrm{ml}$ culture samples using the NucleoSpin RNA II Kit (Macherey Nagel, Düren). When necessary, a second DNase digestion was performed with Turbo-DNase (Ambion) to completely remove the chromosomal DNA. RNA samples were finally stored at $-80^{\circ} \mathrm{C}$.

Antisense probes with a size between 0.2 and $0.5 \mathrm{~kb}$ for the analysis of gene transcription were generated by
PCR and subsequent labelling with DIG RNA-labelling mix (Roche, Mannheim) and T7 polymerase (NEB, Frankfurt). RNA (1 $\mu$ g per time point) was spotted onto nylon membranes using a Schleicher \& Schuell (Dassel) Minifold I Dot Blotter. Hybridization of digoxigeninlabelled RNA probes was detected with X-ray films (Amersham Hyperfilm MP; GE Healthcare) using alkaline phosphatase-conjugated anti-digoxigenin Fab fragments and CSPD as light-emitting substrate as recommended by the supplier (Roche, Mannheim). All experiments were carried out at least twice with independent cultures (biological replicates).

\section{Real-time reverse transcriptase PCR}

For real-time RT-PCR, a MyiQ Single-Color Real-Time PCR Detection System (BioRad, Munich), the iScript One-Step RT-PCR Kit with SYBR Green (Biorad, Munich), $1 \mu \mathrm{M}$ primers, and $100 \mathrm{ng}$ of template RNA were used. Reverse transcription was carried out at $50^{\circ} \mathrm{C}$ for $10 \mathrm{~min}$, the reverse transcriptase was inactivated and the polymerase activated by $5 \mathrm{~min}$ incubation at $95^{\circ} \mathrm{C}, \mathrm{PCR}$ was carried out by 45 cycles of the following program: DNA denaturation for $10 \mathrm{sec}$ at $95^{\circ} \mathrm{C}$, primer annealing for $15 \mathrm{sec}$ at $57^{\circ} \mathrm{C}$, and DNA polymerization for $10 \mathrm{sec}$ at $72^{\circ} \mathrm{C}$. The PCR reaction was followed by a melting curve program $\left(81 \times 55-100^{\circ} \mathrm{C}\right.$ with a heating rate of $1^{\circ} \mathrm{C}$ per $10 \mathrm{sec}$ ) and then a cooling program at $25^{\circ} \mathrm{C}$. Notemplate controls were run with all reactions. Data were analyzed using the MyiQ Single-Color Real-Time PCR Detection System software.

Design of DNA microarrays, RNA quality control, labelling, hybridization and transcriptome analysis

Whole genome expression analyses were performed using custom $M$. smegmatis strain mc $^{2} 1558 \times 15 \mathrm{~K}$ microarrays (Agilent, Santa Clara). Based on annotated genes downloaded from the NCBI genome browser (http://www.ncbi. nlm.nih.gov/genomes), two specific probes per gene were designed using the eArray software (https://earray.chem. agilent.com).

Total RNA from two biological replicates of each bacterial strain or condition was isolated as described above and purified using RNeasy Mini Spin Columns (Qiagen, Hilden, Germany). RNA quantity was measured with the ND-100 Spectrophotometer v3.3.0 (NanoDrop Technologies). RNA integrity was verified using an Agilent RNA 6000 Nano Chip on an Agilent 2100 BioAnalyzer as recommended by manufacturer's protocol (Agilent RNA 6000 Nano Assay Protocol2). Reverse transcription of 300 ng total RNA was carried out, using a random T7N9 primer [36]. Further sample labeling and hybridization was essentially performed as described in the two-color microarray-based gene expression analysis protocol provided by Agilent including the two-color RNA spike-in kit (v5.7, 2008; Agilent 
Technologies, Santa Clara). For each replicate the cy3/cy5 dye combination was flipped between control and experimental sample. Slides were scanned on the Agilent Microarray Scanner with extended dynamic range (XDR) at high resolution $(5 \mu \mathrm{m})$. Data sets were extracted by the feature extraction software package (v9.5.3.1/ Agilent Technologies) using a standard protocol. Data were analyzed using the GeneSpring XI software (Agilent Technologies) with standard settings. Statistically significantly deregulated genes ( $>2$-fold change in comparison to respective control and $\mathrm{p}$-value $<0.05$ ) were identified using the t-test against zero function of GeneSpring XI including the BenjaminiHochberg multiple test correction. The microarray datasets were deposited in GEO database (http://www.ncbi.nlm.nih. gov/geo/) under record number GSE30236.

\section{Purification of GlnR and gel retardation experiments}

For gel shift assays, protein extracts from E. coli Rosetta2 carrying plasmid pMal-c2-glnR were prepared. Cells were cultivated in LB medium containing antibiotics as described, harvested by centrifugation $(4,000 \mathrm{x} \mathrm{g}, 15 \mathrm{~min}$, $4^{\circ} \mathrm{C}$ ) and suspended in $20 \mathrm{mM}$ Tris, $200 \mathrm{mM} \mathrm{NaCl}, 1 \mathrm{mM}$ EDTA, pH ( $\mathrm{HCl}) 7.4\left(2 \mathrm{ml} \mathrm{g}^{-1}\right.$ cell weight $)$ containing lysozyme $\left(2 \mathrm{mg} \mathrm{ml}^{-1}\right)$ and Complete protease inhibitor as recommended by the supplier (Roche, Mannheim). Cells were subsequently disrupted by ultrasonic treatment. Cell debris was removed by centrifugation $(14,000 \mathrm{x}$ g, $30 \mathrm{~min}$, $4^{\circ} \mathrm{C}$ ) and the protein extract was loaded on a $10 \mathrm{ml}$ amylose resin affinity column (GE Healthcare, Munich) in a chromatography device (Äkta prime, GE Healthcare, Munich). Washing and subsequent elution with $20 \mathrm{mM}$ Tris, $200 \mathrm{mM} \mathrm{NaCl}, 1 \mathrm{mM}$ EDTA, $20 \mathrm{mM}$ maltose, $\mathrm{pH}$ ( $\mathrm{HCl}) 7.4$ were carried out as recommended by the supplier of the amylose resin matrix (GE Healthcare, Munich); the purified protein was stored at $4^{\circ} \mathrm{C}$.

Target DNA for the gel shift assays was synthesized by PCR (primers listed in Additional file 1: Table S1) and purified by agarose gel electrophoresis. For labelling of the DNA and the setup of the reaction mixture for the gel shift assay, the DIG Gel Shift Kit (Roche, Mannheim) was used following the supplier's protocol. Separation by gel electrophoresis was performed in native $6 \%$ polyacrylamide gels (Anamed Electrophorese $\mathrm{GmbH}$, Darmstadt) using $0.5 \mathrm{x}$ TBE buffer as running buffer. Subsequently, the labelled DNA was blotted on a nylon membrane (Roche, Mannheim) by electro-blotting as described in the protocol of the DIG Gel Shift Kit (Roche, Mannheim). For detection of the labelled DNA, X-ray films were used.

Purification of AmtR and electrophoretic mobility shift assays For purification of AmtR protein, E. coli BL21 (DE3) carrying plasmid $\mathrm{pQE}-a m t R-\mathrm{His}_{6}$ was used to inoculate $200 \mathrm{ml} \mathrm{LB}$ and the cultures were induced with $0.5 \% \alpha-$ lactose at an $\mathrm{OD}_{600}$ of approximately 0.6 and grown for $12 \mathrm{~h}$ at $16^{\circ} \mathrm{C}$. The cells were harvested by centrifugation, washed twice with lysis buffer (20 mM Tris- $\mathrm{HCl}$, $500 \mathrm{mM} \mathrm{KCl}, 10 \%$ glycerol, $\mathrm{pH}$ 7.9), and resuspended in binding buffer (20 mM Tris- $\mathrm{HCl}, 500 \mathrm{mM} \mathrm{KCl}, 10 \%$ glycerol, $10 \mathrm{mM}$ imidazole, $\mathrm{pH}$ 7.9). The cell suspension was stored on ice for $30 \mathrm{~min}$ and then lysed by sonication. The lysate were centrifuged at 15,000 x $\mathrm{g}$ for $60 \mathrm{~min}$ at $4^{\circ} \mathrm{C}$ and applied to a 1-mL Ni Sepharose column (GE Healthcare) following $1 \mathrm{~h}$ incubation on ice. After washing with $20 \mathrm{ml}$ of binding buffer, the column was washed with $20 \mathrm{ml}$ washing buffer A (20 mM Tris$\mathrm{HCl}, 500 \mathrm{mM} \mathrm{KCl}, 10 \%$ glycerol, $20 \mathrm{mM}$ imidazole, $\mathrm{pH}$ 7.9) and $\mathrm{B}(20 \mathrm{mM}$ Tris- $\mathrm{HCl}, 500 \mathrm{mM} \mathrm{KCl}, 10 \%$ glycerol, $50 \mathrm{mM}$ imidazole, $\mathrm{pH} 7.9)$, respectively. The bound protein was eluted with elution buffer (20 mM Tris$\mathrm{HCl}, 500 \mathrm{mM} \mathrm{KCl}, 10 \%$ glycerol, $500 \mathrm{mM}$ imidazole, $\mathrm{pH}$ 7.9) and the purity of His-tagged protein was checked by $12 \%$ sodium dodecyl sulfate polyacrylamide gel electrophoresis (SDS-PAGE). The purified protein was stored at $-80^{\circ} \mathrm{C}$.

Electrophoretic mobility shift assays (EMSAs) were performed according to the method described before with some modifications [37]. The promoter region of msmeg_2184 (437 bp) was amplified using M. smegmatis genomic DNA as template and the primer pair, msmeg 2184pfw/msmeg_2184prev (see Additional file 1: Table S3). PCR product was labeled at the $5^{\prime}$ ends with $\left[\gamma_{-}{ }^{32} \mathrm{P}\right] \mathrm{ATP}$ using T4 polynucleotide kinase (Promega, China), and purified using illustra ProbeQuant G-50 Micro Columns (GE Healthcare, UK). For EMSA, the ${ }^{32}$ P-labelled DNA probe $(1,000 \mathrm{cpm})$ was incubated individually with various amounts of $\mathrm{His}_{6}$-AmtR protein in $20 \mu \mathrm{l}$ binding assays, containing $2 \mu \mathrm{g}$ sperm DNA, $20 \mathrm{mM}$ Tris- $\mathrm{HCl}$ (pH 7.9), $25 \mathrm{mM} \mathrm{KCl}, 1 \mathrm{mM}$ dithiothreitol (DTT), $5 \mathrm{mM} \mathrm{MgCl}_{2}$, $0.5 \mathrm{mg} \mathrm{ml}^{-1}$ calf BSA and $5 \%$ glycerol. After incubation at $25^{\circ} \mathrm{C}$ for $30 \mathrm{~min}$, protein-bound and -free probe DNA were separated by electrophoresis on non-denaturing $6 \%$ polyacrylamide gels at $10 \mathrm{~V} \mathrm{~cm}^{-1}$ with a running buffer $0.5 \times$ TBE (40 mM Tris- $\mathrm{HCl}, \mathrm{pH} 8.0,20 \mathrm{mM}$ boric acid and $1 \mathrm{mM}$ EDTA). After electrophoresis, gels were dried and scanned with a FLA-7000 phosphoimager (FujiFilm Corporation, Japan).

\section{Availability of supporting data}

The datasets supporting the results of this article are available in the GEO repository (http://www.ncbi.nlm. nih.gov/geo/) under record number GSE30236.

\section{Additional file}

Additional file 1: Table S1. List of all 231 genes with decreased transcript levels in the M. smegmatis wild type strain SMR5 under nitrogen starvation. Table S2. List of all 284 genes with increased 
transcript levels in the M. smegmatis wild type strain SMR5 under nitrogen starvation. Table S3. Primers used in this study. Restriction sites are highlighted bold.

\section{Competing interests}

The authors declare that they have no competing interests.

\section{Authors' contributions}

NJ carried out RNA experiments and growth tests; YL was responsible for AmtR experimental work, while bioinformatic analyses of AmtR were carried out by JA. SR supported the DNA microarray experiments, FT, SS and AB were responsible for general experimental design and supervision of experiments. The manuscript was mainly written by NJ and AB. All authors read and approved the final manuscript.

\section{Acknowledgements}

A.B., J.A. and S.S. were supported by the Deutsche Forschungsgemeinschaft (in frame of SFB 473 and SFB 796); N.J. had a fellowship of the Universität Bayern. Strain SMR5 and plasmids pMN016 and pML814 were kindly provided by M. Niederweis (University of Alabama at Birmingham, AL).

\section{Author details}

${ }^{1}$ Lehrstuhl für Mikrobiologie, Friedrich-Alexander-Universität Erlangen-Nürnberg, Erlangen, Germany. ${ }^{2}$ Key Laboratory of Synthetic Biology, Institute of Plant Physiology and Ecology, Shanghai Institutes for Biological Sciences, Chinese Academy of Sciences, Shanghai, People's Republic of China. ${ }^{3}$ Fachbereich Oecotrophologie, Fachhochschule Münster, Münster, Germany. ${ }^{4}$ Lehrstuhl für Biochemie, Friedrich-Alexander-Universität Erlangen-Nürnberg, Erlangen, Germany.

Received: 12 April 2013 Accepted: 18 November 2013

Published: 22 November 2013

\section{References}

1. Amon J, Titgemeyer F, Burkovski A: Common patterns - unique features: nitrogen metabolism and regulation in Gram-positive bacteria. FEMS Microbiol Rev 2010, 34:588-605.

2. Fink D, Weissschuh N, Reuther J, Wohlleben W, Engels A: Two transcriptional regulators GInR and GInRII are involved in regulation of nitrogen metabolism in Streptomyces coelicolor A3(2). Mol Microbiol 2002, 46:331-347

3. Tiffert Y, Supra P, Wurm R, Wohlleben W, Wagner R, Reuther J: The Streptomyces coelicolor GlnR regulon: identification of new GlnR targets and evidence for a central role of GlnR in nitrogen metabolism in actinomycetes. Mol Microbiol 2008, 67:861-880.

4. Tiffert $Y$, Franz-Wachtel M, Fladerer C, Nordheim A, Reuther J, Wohlleben W, Mast $Y$ : Proteomic analysis of the GInR-mediated response to nitrogen limitation in Streptomyces coelicolor M145. Appl Microbiol Biotechnol 2011, 89:1149-1159.

5. Reuther J, Wohlleben W: Nitrogen metabolism in Streptomyces coelicolor: transcriptional and post-translational regulation. $J$ Mol Microbiol Biotechnol 2007, 12:139-146.

6. Jakoby M, Nolden L, Meier-Wagner J, Krämer R, Burkovski A: AmtR, a global repressor in the nitrogen regulation system of Corynebacterium glutamicum. Mol Microbiol 2000, 37:964-977.

7. Nolden L, Beckers G, Burkovski A: Nitrogen assimilation in Corynebacterium diphtheriae: pathways and regulatory cascades. FEMS Microbiol Lett 2002, 208:287-293.

8. Walter B, Hänßler E, Kalinowski J, Burkovski A: Nitrogen metabolism and nitrogen control in corynebacteria: variations of a common theme. J Mol Microbiol Biotechnol 2007, 12:131-138.

9. Beckers G, Strösser J, Hildebrandt U, Kalinowski J, Farwick M, Krämer R, Burkovski A: Regulation of AmtR-controlled gene expression in Corynebacterium glutamicum: mechanism and characterization of the AmtR regulon. Mol Microbiol 2005, 58:580-595.

10. Buchinger S, Strösser J, Rehm N, Hänßler E, Hans S, Bathe B, Schomburg D, Krämer R, Burkovski A: A combination of metabolome and transcriptome analyses reveals new targets of the Corynebacterium glutamicum nitrogen regulator AmtR. J Biotechnol 2009, 140:68-74.
11. Amon J, Bräu T, Grimrath A, Hänßler E, Hasselt K, Höller M, Jeßberger N, Ott L, Szököl J, Titgemeyer F, Burkovski A: Nitrogen control in Mycobacterium smegmatis: nitrogen-dependent expression of ammonium transport and assimilation proteins depends on the OmpR-type regulator GlnR. $J$ Bacteriol 2008, 190:7108-7106.

12. Amon J, Titgemeyer F, Burkovski A: A genomic view on nitrogen metabolism and nitrogen control in mycobacteria. J Mol Microbiol Biotechnol 2009, 17:20-29.

13. Tatusov RL, Fedorova ND, Jackson JD, Jacobs AR, Kiryutin B, Koonin EV, Krylov DM, Mazumder R, Mekhedov SL, Nikolskaya AN, et al: The COG database: an updated version includes eukaryotes. BMC Bioinformatics 2003, 4:41.

14. Silberbach $M$, Hüser A, Kalinowski J, Pühler A, Walter B, Krämer R, Burkovski $A$ : DNA microarray analysis of the nitrogen starvation response of Corynebacterium glutamicum. J Biotechnol 2005, 119:357-367.

15. Pullan ST, Chandra G, Bibb MJ, Merrick M: Genome-wide analysis of the role of GlnR in Streptomyces venezuelae provides new insights into global nitrogen regulation in actinomycetes. BMC Genomics 2011, 12:175.

16. Ahmad S, Bhatnagar RK, Venkitasubramanian TA: Changes in the enzyme activities involved in nitrogen assimilation in Mycobacterium smegmatis under various growth conditions. Ann Inst Pasteur Microbiol 1986 137B:231-237.

17. Iwainsky $H$, Sehrt I: The nitrogen metabolism of mycobacteria. Z Tuberk Erkr Thoraxorg 1968, 128:145-150.

18. Sritharan V, Ratledge C, Wheeler PR: Effect of homoserine on growth of Mycobacterium smegmatis: inhibition of glutamate transport by homoserine. J Gen Microbiol 1987, 133:2781-2785.

19. Nolden L, Beckers G, Möckel B, Pfefferle W, Nampoothiri KM, Krämer R, Burkovski A: Urease of Corynebacterium glutamicum: organization of corresponding genes and investigation of activity. FEMS Microbiol Lett 2000, 189:305-310.

20. Puskás LG, Inui M, Yukawa H: Structure of the urease operon of Corynebacterium glutamicum. DNA Seq 2000, 11:383-394. 467.

21. Mongodin EF, Shapir N, Daugherty SC, DeBoy RT, Emerson JB, Shvartzbeyn A, Radune D, Vamathevan J, Riggs F, Grinberg V, et al: Secrets of soil survival revealed by the genome sequence of Arthrobacter aurescens TC1. PLoS Genet 2006, 2:e214

22. Nishio Y, Nakamura Y, Kawarabayasi Y, Usuda Y, Kimura E, Sugimoto S, Matsui K, Yamagishi A, Kikuchi H, Ikeo K, Gojobori T: Comparative complete genome sequence analysis of the amino acid replacements responsible for the thermostability of Corynebacterium efficiens. Genome Res 2003, 13:1572-1579.

23. Gartemann KH, Abt B, Bekel T, Burger A, Engemann J, Flügel M, Gaigalat L, Goesmann A, Gräfen I, Kalinowski J, et al: The genome sequence of the tomato-pathogenic actinomycete Clavibacter michiganensis subsp. michiganensis NCPPB382 reveals a large island involved in pathogenicity. J Bacteriol 2008, 190:2138-2149.

24. Bagwell CE, Bhat S, Hawkins GM, Smith BW, Biswas T, Hoover TR, Saunders E, Han CS, Tsodikov OV, Shimkets $\sqcup$ : Survival in nuclear waste, extreme resistance, and potential applications gleaned from the genome sequence of Kineococcus radiotolerans SRS30216. PLoS One 2008, 3:e3878.

25. Ishikawa J, Yamashita A, Mikami Y, Hoshino Y, Kurita H, Hotta K, Shiba T, Hattori M: The complete genomic sequence of Nocardia farcinica IFM 10152. Proc Natl Acad Sci USA 2004, 101:14925-14930.

26. Omura S, Ikeda H, Ishikawa J, Hanamoto A, Takahashi C, Shinose M, Takahashi Y, Horikawa $\mathrm{H}$, Nakazawa $\mathrm{H}$, Osonoe $\mathrm{T}$, et al: Genome sequence of an industrial microorganism Streptomyces avermitilis: deducing the ability of producing secondary metabolites. Proc Natl Acad Sci USA 2001, 98:12215-12220.

27. Ramos JL, Martínez-Bueno M, Molina-Henares AJ, Terán W, Watanabe K, Zhang X, Gallegos MT, Brennan R, Tobes R: The TetR family of transcriptional repressors. Microbiol Mol Biol Rev 2005, 69:326-356.

28. Silberbach $M$, Schäfer $M$, Hüser AT, Kalinowski J, Pühler A, Krämer R, Burkovski A: Adaptation of Corynebacterium glutamicum to ammonium limitation: a global analysis using transcriptome and proteome techniques. Appl Environ Microbiol 2005, 71:2391-23402.

29. Deutscher J: The mechanisms of carbon catabolite repression in bacteria. Curr Opin Microbiol 2008, 11:87-93.

30. Görke B, Stülke J: Carbon catabolite repression in bacteria: many ways to make the most out of nutrients. Nat Rev Microbiol 2008, 6:613-624.

31. Sambrook J, Fritsch EF, Maniatis T: Molecular Cloning. A Laboratory Handbook. 2nd edition. Cold Spring Harbor, N.Y: Cold Spring Harbor Laboratory Press; 1989 
32. Grant SG, Jessee J, Bloom FR, Hanahan D: Differential plasmid rescue from transgenic mouse DNAs into Escherichia coli methylation-restriction mutants. Proc Natl Acad Sci USA 1990, 87:4645-4649.

33. Belisle JT, Sonnenberg MG: Isolation of genomic DNA from mycobacteria. Methods Mol Biol 1998, 101:31-44.

34. Stephan J, Stemmer V, Niederweis M: Consecutive gene deletions in Mycobacterium smegmatis using the yeast FLP recombinase. Gene 2004, 343:181-190.

35. Stephan J, Bender J, Wolschendorf F, Hoffmann C, Roth E, Mailänder C, Engelhardt $\mathrm{H}$, Niederweis $\mathrm{M}$ : The growth rate of Mycobacterium smegmatis depends on sufficient porin-mediated influx of nutrients. Mol Microbiol 2005, 58:714-730.

36. Moreno-Paz M, Parro V: Amplification of low quantity bacterial RNA for microarray studies: time-course analysis of Leptospirillum ferrooxidans under nitrogen-fixing conditions. Environ Microbiol 2006, 8:1064-1073.

37. Li R, Xie Z, Tian Y, Yang H, Chen W, You D, Liu G, Deng Z, Tan H: polR, a pathway-specific transcriptional regulatory gene, positively controls polyoxin biosynthesis in Streptomyces cacaoi subsp. asoensis. Microbiology 2009, 155:1819-1831.

doi:10.1186/1756-0500-6-482

Cite this article as: Jeßberger et al:: Nitrogen starvation-induced transcriptome alterations and influence of transcription regulator mutants in Mycobacterium smegmatis. BMC Research Notes 2013 6:482.

\section{Submit your next manuscript to BioMed Central and take full advantage of:}

- Convenient online submission

- Thorough peer review

- No space constraints or color figure charges

- Immediate publication on acceptance

- Inclusion in PubMed, CAS, Scopus and Google Scholar

- Research which is freely available for redistribution 